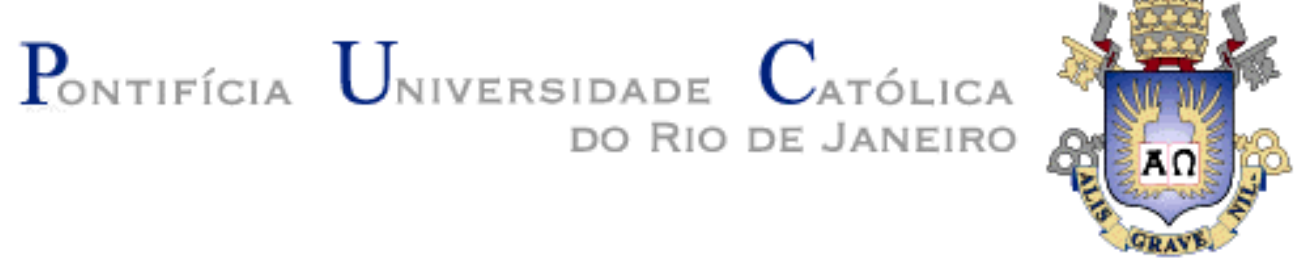

Daniela Garcia Medeiros

Produção e Caracterização de Nanocompósitos de Nylon 11 Reforçados por Nanocargas a base de $\mathrm{TiO}_{2}$

Dissertação apresentada como requisito parcial para obtenção do título de Mestre pelo Programa de Pós Graduação em Engenharia de Materiais e de Processos Químicos e Metalúrgicos da PUCRio.

Orientadora: Prof. Paula Mendes Jardim Co-Orientador: Prof. José Roberto Moraes D’Almeida 


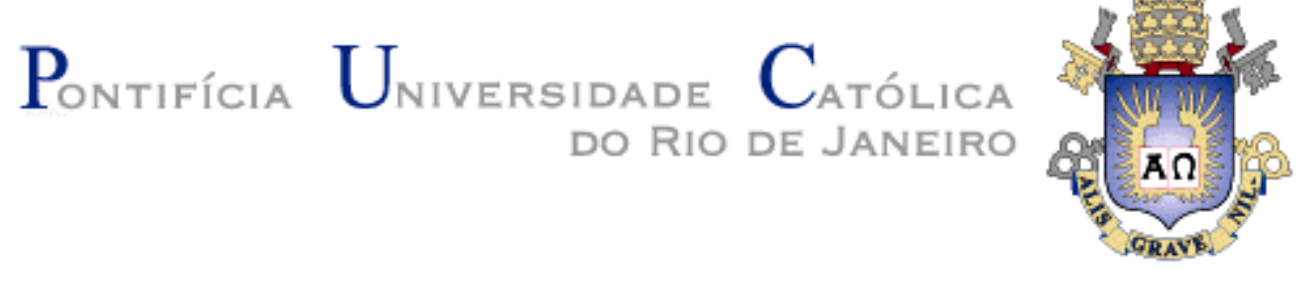

Daniela Garcia Medeiros

\section{Produção e Caracterização de Nanocompósitos de Nylon 11 Reforçados por Nanocargas a base de $\mathrm{TiO}_{2}$}

Dissertação apresentada como requisito parcial para obtenção do título de Mestre pelo Programa de Pós Graduação em Engenharia de Materiais e de Processos Químicos e Metalúrgicos da PUCRio.

Prof ${ }^{\circ}$ Paula Mendes Jardim Orientadora e Presidente Universidade Federal do Rio de Janeiro - UFRJ

Prof ${ }^{\circ}$ José Roberto Moraes d'Almeida Co-Orientador Departamento de Engenharia de Materiais - PUC-Rio

Prof: Fernando Cosme Rizzo Assunção Departamento de Engenharia de Materiais - PUC-Rio

Prof ${ }^{\circ}$ Bojan Marinkovic Departamento de Engenharia de Materiais - PUC-Rio

Veronica Maria de Araujo Calado Universidade Federal do Rio de Janeiro - UFRJ

Prof ${ }^{\circ}$ José Eugenio Leal Coordenador Setorial de Pós-Graduação do Centro Técnico Científico da PUC-Rio 
Todos os direitos reservados. É proibida a reprodução total ou parcial do trabalho sem autorização da universidade, da autora e do orientador.

\section{Daniela Garcia Medeiros}

Formada em Engenharia Metalúrgica pela Pontifícia Universidade Católica do Rio de Janeiro (PUC-Rio) em 2008.

Ficha Catalográfica

Medeiros, Daniela Garcia

Produção e caracterização de nanocompósitos de Nylon 11 reforçados por nanocargas a base de $\mathrm{TiO} 2 /$ Daniela Garcia Medeiros ; orientadora: Paula Mendes Jardim ; co-orientador: José Roberto Moraes D'Almeida. 2012.

74 f. : il. (color.) ; $30 \mathrm{~cm}$

Dissertação (mestrado)-Pontifícia Universidade Católica do Rio de Janeiro, Departamento de Engenharia de Materiais, 2012.

Inclui bibliografia

1. Engenharia de materiais - Teses. 2. Nanocompósitos. 3. Nanotubos de titanato. 4. Nanopartículas de TiO2. 5. Nylon 11. I. Jardim, Paula Mendes. II. D’Almeida, José Roberto Moraes. III. Pontifícia Universidade Católica do Rio de Janeiro. Departamento de Engenharia de Materiais. IV. Título.

CDD: 620.11 
Para as três mulheres mais importantes da minha vida, Ana Luisa, Carolina e Vera, por todo apoio, confiança e amor. 


\section{Agradecimentos}

À minha orientadora Paula Jardim por todos os ensinamentos e orientações e por estar ao me lado acreditando em mim desde a graduação. A ela agradeço não só pelo conhecimento, mas também pela amizade durante todos esses anos.

Ao meu co-orientador José Roberto d'Almeida, pela orientação e ensinamentos e por todo apoio cedido durante a elaboração da tese.

À PUC-Rio pelos auxílios concedidos, sem os quais este trabalho não poderia ter sido realizado.

À Ana Luisa, que sempre me apoiou nos momentos mais difíceis e me deu o devido suporte para que eu chegasse até aqui. A sua amizade e companheirismo foram peças fundamentais na minha vida.

À minha mãe Vera que com seu carinho e amor incondicional esteve sempre ao meu lado torcendo pelas minhas vitórias.

À minha irmã Carolina e meu cunhado Elísio que sempre me incentivaram a alcançar meus objetivos.

A todos os meus familiares e amigos, por fazerem parte da minha vida e por todo amor e carinho sempre presentes.

Ao Marcelo Ferreira, por toda a ajuda na fabricação e caracterização das amostras e por todo conhecimento fornecido. Sua contribuição foi fundamental para o desenvolvimento desta tese. 
À Marcia Gomes de Oliveira, tecnologista da Divisão de Caracterização e Processamento de Materiais (DPCM) do Instituto Nacional de Tecnologia (INT), por disponibilizar seu aluno Marcelo, bem como todos os equipamentos do INT.

À Verônica Calado, por ter disponibilizado seu laboratório para as análises térmicas, e por todos os conhecimentos passados. E também a Rosana, por ter realizado todos os ensaios térmicos no laboratório.

À todos os membros do Departamento de Engenharia de Materiais da PUC-Rio, por todo apoio e ajuda ao longo de todos esses anos. 


\section{Resumo}

Medeiros, Daniela Garcia; Jardim, Paula Mendes (Orientadora); d'Almeida, José Roberto (Co-Orientador). Produção e Caracterização de Nanocompósitos de Nylon 11 Reforçados por Nanocargas a base de TiO $_{2}$. Rio de janeiro, 2012. 74p. Dissertação de Mestrado - Departamento de Engenharia de Materiais, Pontifícia Universidade Católica do Rio de Janeiro.

A rápida evolução tecnológica vem acompanhada da necessidade de se obter cada vez mais materiais com melhores desempenhos. Os materiais poliméricos, muito utilizados em nosso cotidiano devido as suas características de boa resistência, boa estabilidade química, fácil processabilidade e baixo custo, ainda são restritos para algumas aplicações devido as suas baixas propriedades mecânicas e térmicas, quando comparados ao aço. A fim de atender a essas características, os materiais compósitos à base de polímeros vêm ganhando um importante espaço. Muito já foi relatado sobre a eficiência da inclusão de cargas em escala nanométrica em uma matriz polimérica, para se obter melhoras nas propriedades térmicas e mecânicas. A poliamida 11, muito utilizada em aplicações offshore como revestimento de risers, é um exemplo de polímero que pode possuir melhores propriedades com a aplicação de reforços. Os nanotubos de titanato apresentam boas características mecânicas com módulo de Young em torno de $230 \mathrm{GPa}$ e se apresentam como uma boa carga para nanocompósitos. Sendo assim, no presente trabalho foram fabricados compósitos à base de poliamida 11 com cargas de nanotubos de titanano (TTNT) e nanopartículas de $\mathrm{TiO}_{2}$. Os nanotubos utilizados possuem estrutura de trititanatos $\mathrm{e}$ as nanopartículas são do tipo comercial P-25 e foram utilizadas no intuito de comparar os resultados obtidos com os nanotubos, uma vez que estas possuem uma área superficial bem menor. Os nanocompósitos fabricados (A1, A2, A3 e A4) e a poliamida 11 pura (A0 e Ap) foram submetidos a ensaios de tração, termogravimetria (TGA) e microscopia eletrônica de varredura (MEV). Foi observada uma melhora significativa nas propriedades mecânicas para as amostras A1 e A3 e nas propriedades térmicas para as amostras A1, A3 e A4, quando comparadas com a poliamida pura.

\section{Palavras-chave}

Nanocompósitos; nanotubos de titanato; nanopartículas de $\mathrm{TiO}_{2}$; nylon 11 


\section{Abstract}

Medeiros, Daniela Garcia; Jardim, Paula Mendes (Advisor); d'Almeida, José Roberto (Co-Advisor). Production and Characterization of Nylon 11 Nanocomposites Reinforced with $\mathrm{TiO}_{2}$ based Nanomaterials. Rio de janeiro, 2012. 74p. MSc. Dissertation - Departamento de Engenharia de Materiais, Pontifícia Universidade Católica do Rio de Janeiro.

The fast technological developments comes with the need to obtain more materials combined with better performance. Polimeric materials, commonly used in our daily because of its characteristics of good strength, good chemical stability, easy processability and low cost, are still restricted for some applications owing to their low mechanical and thermal properties compared to steel. In order to improve these characteristics, composite materials based on polymers are gaining an important space. Much has been reported on the effectiveness of inclusion of fillers at nanoscale in a polymer matrix, to obtain improvements in mechanical and thermal properties. The polyamide 11, widely used in offshore applications as coatings of risers, is one example of polymer which can has better properties with the use of reinforcement. The titanate nanotubes exhibit good mechanical properties with Young's modulus around $230 \mathrm{GPa}$ and appear as good nanocomposite reinforcement. In this study, polyamide 11 composites reinforced with titanate nanotubes (TTNT) and $\mathrm{TiO}_{2}$ nanoparticles were manufactured. The nanotubes used have trititanate structure and the nanoparticles are the commercial type P-25 and were used in order to compare the results with the nanotubes, as the nanoparticles have a smaller surface area. The nanocomposites produced (A1, A2, $\mathrm{A} 3$ and $\mathrm{A} 4$ ) and pure polyamide 11 (A0 and Ap) were submitted to tensile tests, thermogravimetric analysis (TGA) and scanning electron microscopy (SEM). A significant improvement on mechanical properties for samples A1 and A3 and for thermal properties in samples A1, A3 and A4 were observed when compared to pure polyamide

\section{Keywords}

Nanocomposites; titanate nanotubes; $\mathrm{TiO}_{2}$ nanoparticles; nylon 11 


\section{Sumário}

1 Introdução

2 Revisão Bibliográfica

$\begin{array}{ll}2.1 \text { Nanocompósitos } & 17\end{array}$

$\begin{array}{ll}2.2 \text { Nanocompósitos com matriz de Nylon } 11 & 19\end{array}$

$\begin{array}{ll}\text { 2.2.1 Nylon } & 19\end{array}$

$\begin{array}{ll}\text { 2.2.2 Síntese e Estrutura } & 20\end{array}$

$\begin{array}{ll}2.2 .3 \text { Nylon } 11 & 21\end{array}$

2.2.4 Nanocompósitos $\quad 24$

2.3 Nanocompósitos com matriz polimérica e carga de nanomateriais 1D $\begin{array}{ll}\text { baseados em } \mathrm{TiO}_{2} & 26\end{array}$

2.4 Nanocompósitos com matriz polimérica e carga de nanopartículas de $\begin{array}{ll}\mathrm{TiO}_{2} & 30\end{array}$

2.5 Propriedades mecânicas dos polímeros 32

2.5.1 Ensaios de Tração 34

3 Objetivo 36

4 Materiais e Métodos $\quad 37$

$\begin{array}{ll}\text { 4.1 Materiais } & 37\end{array}$

4.2 Método de fabricação dos nanocompósitos 37

4.2.1 Poliamida $11 \quad 38$

4.2.2 Fabricação dos nanocompósitos $\quad 39$

4.3 Técnicas de Caracterização 42

4.3.1 Microscópio Eletrônico de Varredura (MEV) 42 
4.3.2 Ensaio de Tração 42

4.3.3 Análise Termogravimétrica (TGA) 43

5 Resultados e Discussão 44

5.1 Microscópio Eletrônico de Varredura (MEV) 44

5.2 Ensaio de Tração 49

5.3 Termogravimetria (TGA) 57

6 Conclusões 62

7 Sugestões $\quad 64$

8 Bibliografia $\quad 65$

9 Apêndice $\quad 72$ 


\section{Lista de Figuras}

$\begin{array}{ll}\text { Figura 1: Formas dimensionais dos nanomateriais. } & 18\end{array}$

Figura 2: Exemplo de moléculas de nylon 6 e nylon 6,6. 21

Figura 3: Monômero do Nylon 11.

Figura 4: Imagem de um duto flexível e suas diversas camadas. 23

Figura 5: Exemplos de aplicações da poliamida 11.

Figura 6: Resultados do TGA da PA11 pura e dos nanocompósitos com $\begin{array}{ll}\text { diversas concentrações. } & 25\end{array}$

Figura 7: Resultados da PA11 pura e dos nanocompósitos com diversas concentrações (a) DMA; (b) Ensaio de tração.

Figura 8: Esquema da transformação das nanoestruturas através do método hidrotérmico alcalino.

Figura 9: Imagens de MET dos nanotubos de titanato utilizados neste $\begin{array}{lr}\text { trabalho. } & 28\end{array}$

Figura 10: Estrutura do trititanato.

Figura 11: Imagens de MET e difração de elétrons do P-25 nas regiões

(a) da fase anátsio e (b) na fase rutilo.

Figura 12: 3 tipos de curva tensão $x$ deformação para polímeros.

Figura 13: Diagrama de blocos das etapas do preparo e caracterização dos nanocompósitos.

Figura 14 - Imagens do misturador utilizado na etapa de dispersão.

Figura 15 - Imagem dos corpos de prova feitos na etapa de injeção.

Figura 16 - Corpo de prova utilizado para o ensaio de tração.

Figura 17 - Imagens de MEV das amostras A1, A2, A3 e A4 revelando a presença de cargas aglomeradas na matriz. 
Figura 19 - Imagem de MEV e EDS na amostra A2. 45

Figura 20 - Imagem de MEV e EDS na amostra A3. 46

Figura 21 - Imagem de MEV e EDS na amostra A4. 46

Figura 22 - Representação esquemática do crazing.

Figura 23 - Imagens de MEV da amostra A3 comprovando a ocorrência de crazing com aumentos de (a) 50X e (b) 200X.

Figura 24 - Imagens de MEV das amostras (a) A1, (b) A2, (c) A3 e (d) A4, evidenciando a aglomeração das cargas nos poros

Figura 25 - Curvas tensão x deformação das amostras A0, A1 e A3 a uma velocidade de carregamento de $50 \mathrm{~mm} / \mathrm{min}$.

Figura 26 - Curvas tensão $\mathrm{x}$ deformação para as diferentes velocidades de carregamento do ensaio de tração para amostra: (a) A1 e (b) A3.

Figura 27 - Micrografia da amostra A0.

Figura 28 - Linearização da curva da amostra A1.

Figura 29 - (a) Curvas da TGA e (b) curvas da 1a derivada da TGA.

Figura 30 - Primeiro estágio de perda de massa da poliamida 11(A0 e Ap) e dos nanocompósitos (A1, A2, A3 e A4).

Figura 31 - Curvas de TGA dos nanotubos de titanato (TTNT) e das nanopartículas comerciais (P-25). 


\section{Lista de Tabelas}

Tabela 1 - Propriedades típicas dos polímeros industriais mais utilizados.

Tabela 2 - Nomenclatura adotada para as amostras de acordo com o percentual de carga.

Tabela 3 - Parâmetros utilizados na injeção.

Tabela 4 - Propriedades mecânicas da PA11 e dos nanocompósitos fabricados.

Tabela 5 - \% massa perdida e temperatura de degradação das amostras.

60 


\section{Lista de Gráficos}

Gráfico 1 - (a) Tensão, (b) Deformação, (c) Módulo de elasticidade e

(d) Coeficiente de encruamento 


\section{1.}

\section{Introdução}

A evolução industrial e a notável dependência do petróleo é um tema de preocupação mundial. Sendo este um recurso não renovável, e considerando a velocidade de consumo atual, estima-se que em 50 anos o mundo enfrentará uma crise de energia de proporções inestimáveis. Na tentativa de evitar tal colapso, muitos materiais que não são provenientes do petróleo vêm sendo estudados e a poliamida 11 é um dos materiais que se encaixa nessa tendência. Ao contrário de outros plásticos de engenharia como polipropileno, poliamida 6, poliestireno, entre outros, a poliamida 11 (ou nylon 11) é proveniente de um recurso natural renovável, a mamona [1].

Por apresentar características como flexibilidade, alta resistência à fadiga em flexão, alta resistência ao impacto, baixa fluência e resistência ao envelhecimento e degradação, a poliamida se tornou um material chave tanto para aplicações na indústria "offshore”, como revestimento para dutos flexíveis, quanto em circuitos eletrônicos e componentes para aplicações de alto desempenho [2].

Entretanto, com o rápido desenvolvimento tecnológico, também se fez necessário o desenvolvimento de materiais com melhores desempenhos, o que fez com que o estudo de nanocompósitos poliméricos tenha se difundido rapidamente. A aplicação de cargas em escala nanométricas a uma matriz polimérica, já teve sua eficiência comprovada por muitos pesquisadores e se destaca por melhorar propriedades como térmicas, elétricas, ópticas e mecânicas [3-9].

Nanoargilas [4,10], nanotubos de carbono [3,6,11,12], nanopartículas de $\mathrm{TiO}_{2}$ [13-15] e nanotubos de titanato [16-20] são algumas das cargas de especial interesse utilizadas em nanocompósitos poliméricos. Dentre suas aplicações comerciais podemos citar artigos esportivos, componentes aeroespaciais, componentes para automóveis, etc [21].

Sendo assim, o presente trabalho visa reportar o comportamento térmico e mecânico de nanocompósitos com matriz polimérica (nylon 11) reforçados por 
nanocargas de nanotubos de titanato e nanopartículas de $\mathrm{TiO}_{2}$ (comercial do tipo P-25). Para lidar com a aglomeração, que normalmente ocorre quando se emprega partículas de pequenas dimensões, foi feita uma dispersão anterior à mistura dos materiais que será descrita em detalhes mais adiante. A escolha do polímero se deu devido a sua aplicação em itens de alto desempenho como risers e circuitos eletrônicos, entre outros. 


\section{2.}

\section{Revisão Bibliográfica}

\subsection{Nanocompósitos}

Nanocompósitos podem ser definidos como a união de dois ou mais materiais onde ao menos um deles possui dimensões na escala nanométrica $\left(10^{-9} \mathrm{~m}\right)$. A combinação entre as características dos nanomateriais como, tamanho, propriedades mecânicas e a adição de baixas concentrações em uma matriz, é um dos principais atrativos para o desenvolvimento crescente dos nanocompósitos. Outra vantagem desses materiais é o fato de que muitos nanocompósitos podem ser fabricados e processados de formas similares aos compósitos convencionais [21].

Nanomateriais pertencem a uma classe de materiais com tamanho menor que $100 \mathrm{~nm}$ e cuja microestrutura pode ter de zero a três formas dimensionais (figura 1), sendo 0-D composta por nanopartículas, 1-D por nanofios, nanotubos e nanofitas, 2-D nanofilmes e nanoplacas e 3-D materiais volumétricos, onde o número representa as dimensões que não estão em escala nanométrica [22]. Os nanocompósitos são um exemplo de forma dimensional 3-D. Apesar de não possuírem nenhuma das dimensões em escala nanométrica, estes possuem a presença de materiais (cargas) que estão em nanoescala. No presente trabalho, utilizaremos dois tipos de cargas com formas dimensionais diferentes, nanopartículas (0-D) e nanotubos (1-D). 


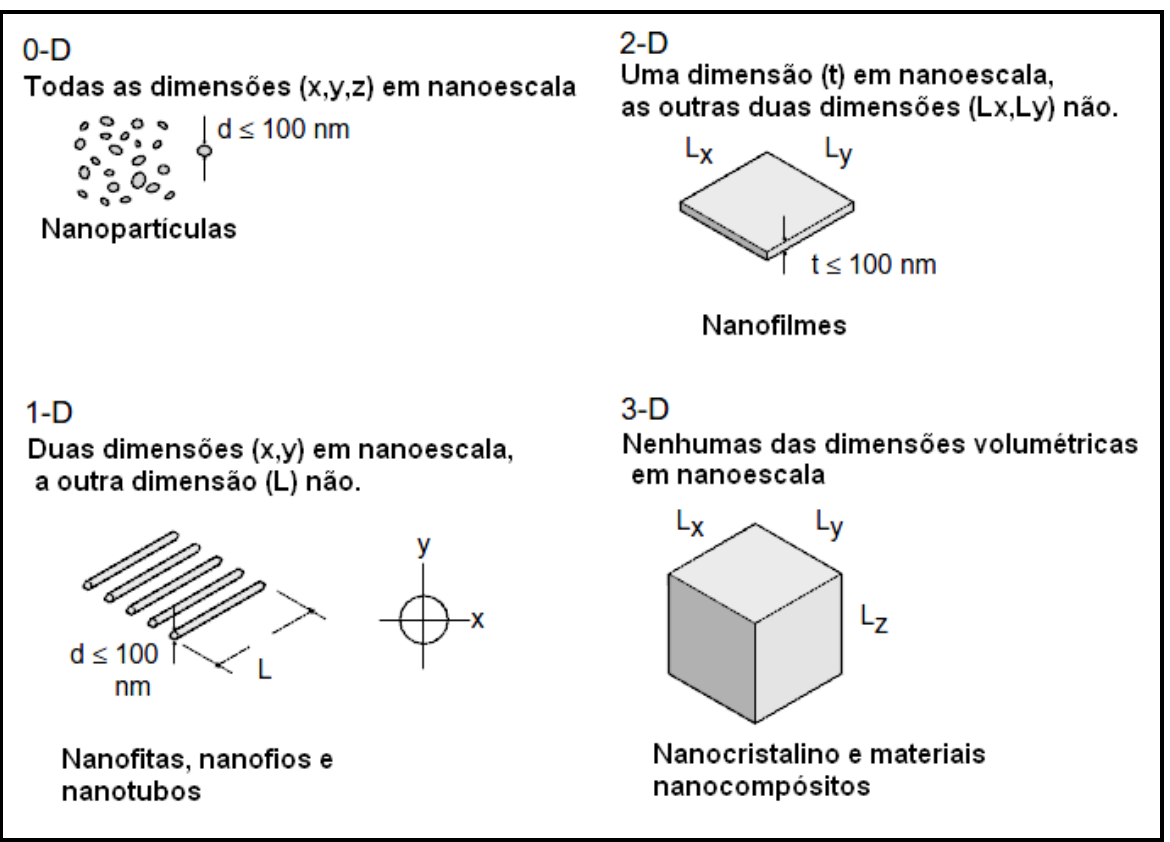

Figura 1 - Formas dimensionais dos nanomateriais [22].

Os nanotubos ganharam particular interesse a partir da descoberta feita por Iijima em 1991 [23] onde foram sintetizados os primeiros nanotubos de carbono. A partir daí, foram reportadas sínteses de nanotubos de uma série de outros materiais como o óxido de vanádio $\left(\mathrm{V}_{2} \mathrm{O}_{5}\right)$ [11,24,25], óxido de alumínio $\left(\mathrm{Al}_{2} \mathrm{O}_{3}\right)$ [25], dióxido de silício $\left(\mathrm{SiO}_{2}\right)$ [25,26] e óxido de titânio $\left(\mathrm{TiO}_{2}\right)$ [16-20].

Dentre os nanocompósitos mais estudados podemos destacar os que possuem matriz polimérica. Apesar de possuir características como facilidade de processamento, baixa densidade e ductilidade, os polímeros possuem baixo módulo de elasticidade, quando comparados a metais e cerâmicos [27]. Entretanto, estes vêm apresentando melhora significativa nas propriedades térmicas, elétricas e mecânicas quando combinados a nanomateriais. Alguns exemplos reportados na literatura podem ser citados como o nylon 6 reforçado por $5 \%$ p de nanopartículas de sílica, onde houve um aumento de $15 \%$ na resistência a tração, 23\% no módulo de Young e 78\% na resistência ao impacto [28]. Ma et al [29] reportaram nanocompósitos a base de polietileno reforçados com nanopartículas de $\mathrm{TiO}_{2}$ funcionalizadas onde houve melhoras nas propriedades elétricas. Gojny et al. [3] avaliaram a condutividade térmica e elétrica em nanocompósitos de epóxi com nanotubos de carbono e relataram um aumento 
dessas propriedades. Santos et al. [4] evidenciaram o aumento na resistência ao impacto e do módulo de Young em polipropileno combinado com nanorgilas.

Um dos pioneiros na pesquisa sobre nanocompósitos à base de nylon, foi o Toyota Central Research Laboratories, no Japão, que reportou no início dos anos 90 um trabalho sobre nanocompósitos com matriz em nylon 6, onde a adição de uma quantidade muito pequena de carga resultou numa melhora significativa das propriedades térmicas e mecânicas [21].

Muitos estudos têm sido feitos utilizando o nylon 11 como matriz polimérica em nanocompósitos, sendo as principais cargas utilizadas as nanoargilas [10,30], nanoestruturas de carbono [5,6,12] e sílica [27]. Pouco se encontra na literatura sobre a utilização de nanopartículas de $\mathrm{TiO}_{2}$ como cargas para poliamidas [31] e a utilização de nanotubos de titanato ainda não foi bem documentada.

\subsection{Nanocompósitos com matriz de Nylon 11}

\subsubsection{Nylon}

O Nylon ou poliamida (PA) é um polímero termoplástico sintético e foi produzido pela primeira vez em 1935 pela DuPont. Inicialmente foi introduzido na forma de fibras, entretanto, sua aplicação aumentou consideravelmente e hoje pode ser encontrado na forma de filmes, fibras, extrudados, injetados e moldados, entre outros [2].

As poliamidas mais comuns são a 6 e 6,6 devido as suas características de baixa densidade, baixo coeficiente de atrito, isolamento elétrico e resistência ao desgaste. Elas possuem uma grande utilização na indústria mecânica, elétrica e química e ganharam importante espaço na construção civil na substituição de metais convencionais [21].

A poliamida 11 é um importante polímero comercial com excelentes características de piezoeletricidade, ferroeletricidade e propriedades mecânicas. Podemos citar dentre as indústrias que mais a utilizam a indústria automobilística 
e a indústria petrolífera. Nessa última a poliamida é usada como revestimento de tubulações flexíveis (risers), que são utilizados para o transporte do petróleo.

\subsubsection{Síntese e Estrutura}

A estrutura da poliamida é formada por monômeros de amidas (-CONH-). A amida é formada pela união de uma amina $\left(-\mathrm{NH}_{3}\right)$ e uma carboxila (-COOH-) que ao reagirem liberam uma molécula de água. Este tipo de ligação é chamado de ligação peptídica.

As poliamidas são diferenciadas de acordo com a sua estrutura. Métodos distintos podem ser aplicados para a síntese das poliamidas, sendo eles [32]:

(1) Policondensação de diaminas e ácidos dicarboxílicos;

(2) Policondensação de ácidos carboxílicos $\omega$-aminos;

(3) Abertura do anel e polimerização (ou poliadição) de amidas cíclicas.

Sua identificação é feita por um sistema numérico. A presença de apenas um número (ex.: Poliamida 6) significa que ela foi formada a partir de um único monômero (homopolímero), já a presença de dois números separados por vírgula (ex.: Poliamida 6,6), indica que dois monômeros diferentes foram utilizados na sua produção (copolímeros). O número também representa a quantidade de átomos de carbono existente no monômero (figura 2) [2]. 


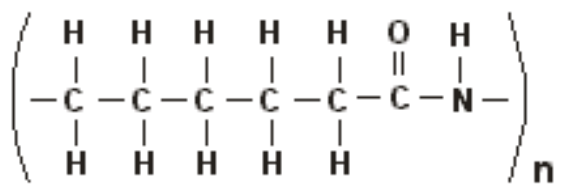

nylor-6

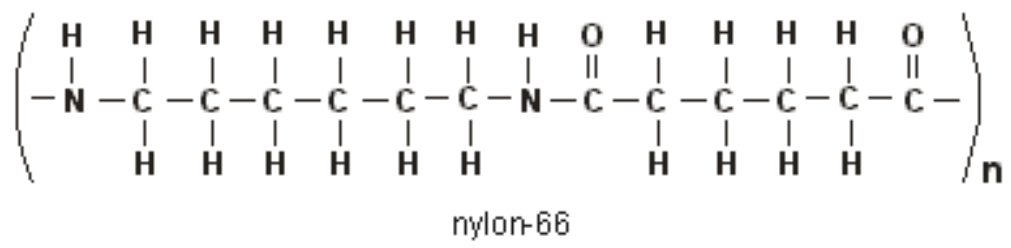

Figura 2 - Exemplo de moléculas de nylon 6 e nylon 6,6 [33].

Uma característica importante das poliamidas é a estrutura cristalina que é formada por regiões cristalinas empacotadas e unidas por regiões amorfas (formadas por ligações de hidrogênio). Diferentemente de outros polímeros, o processamento influencia diretamente na sua cristalinidade. Assim, por exemplo, a poliamida 6 ao ser resfriada bruscamente pode exibir cristalinidade de apenas $10 \%$, ao passo que se resfriada lentamente este índice pode chegar a $60 \%$ [2].

\subsubsection{Nylon 11}

O Nylon 11 (figura 3) é um derivado do óleo vegetal (mamona) não biodegradável. Com uma temperatura de fusão de $180^{\circ} \mathrm{C}$, este é um dos plásticos de engenharia de alta performance, com características como resistência química, alta resistência ao impacto tanto à temperatura ambiente como em baixas temperaturas e boa estabilidade dimensional devido a baixa absorção de água [1]. Entretanto, seu custo ainda é elevado, o que limita sua aplicação em outros segmentos, além da indústria do petróleo. 


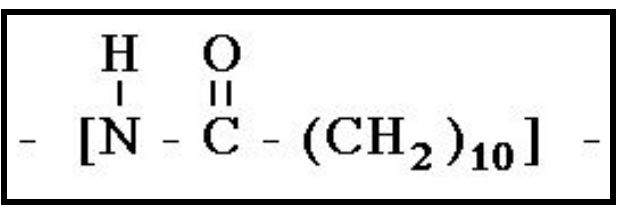

Figura 3: Monômero do Nylon 11.

A baixa absorção de água desse material está diretamente ligada à concentração do grupamento amida. Logo, quanto maior o número de grupos de metilenos na cadeia linear, menor será a absorção de água, uma vez que o aumento da cadeia linear diminui as ligações de hidrogênio responsáveis pela absorção de água [32].

Sua estrutura apresenta partes cristalinas e uma grande fração de material amorfo. Isso ocorre principalmente devido à polidispersividade do material, que dificulta o ordenamento e a cristalização [2].

Para determinar a cristalinidade da poliamida 11 obtida comercialmente, Dhanalakshmi et al [34] dividiram o valor do calor de fusão $(\Delta \mathrm{H})$ da amostra obtida pelo calor de fusão de uma amostra de nylon $11100 \%$ cristalina $\left(\Delta \mathrm{H}^{\circ}=\right.$ $206 \mathrm{~J} / \mathrm{g}$ ) e o grau de cristalinidade encontrado foi de $15,8 \%$. Outros autores também utilizaram o mesmo método de medição e encontraram um teor de cristalinidade de $25 \%$ [35], o que comprova que o grau de cristalinidade pode variar bastante e depende diretamente do processamento.

Dentre as principais aplicações da poliamida 11, pode-se citar a indústria offshore, onde surgiu como um dos primeiros materiais para a fabricação de dutos flexíveis (figura 4). Por ser um material termoplástico, pode ser processado facilmente via extrusão, em tubos de diâmetros, espessuras e comprimentos variados, em um processo contínuo. Aliado a isso, também possui características de resistência à fluência, resistência à fadiga, boa resistência à tração e é uma excelente barreira química ao óleo e ao gás natural [2].

$\mathrm{Na}$ indústria petrolífera alguns exemplos da utilização da poliamida em dutos flexíveis podem ser citados, tais como: camada interna de revestimento, promovendo a estanqueidade da linha e ficando em contato direto com os fluidos; camada externa promovendo resistência à corrosão marinha e à entrada de água; e 
como camada intermediária onde atua reduzindo o atrito entre as camadas metálicas.

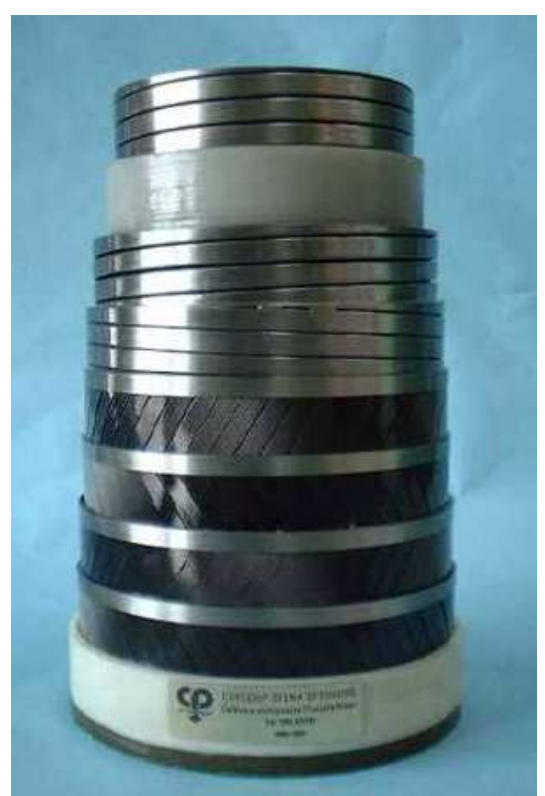

Figura 4 - Imagem de um duto flexível e suas diversas camadas [36].

A temperatura de transição vítrea da poliamida possui valores próximos a $45^{\circ} \mathrm{C}$, porém, este valor pode variar até $0^{\circ} \mathrm{C}$ caso o material possua um elevado teor de plastificantes, o que aumenta sua tenacidade e resistência ao impacto. A poliamida é utilizada também em aplicações de alto desempenho como em componentes de dispositivos eletrônicos, automóveis, fios e cabos, indústria têxtil, etc (figura 5). 

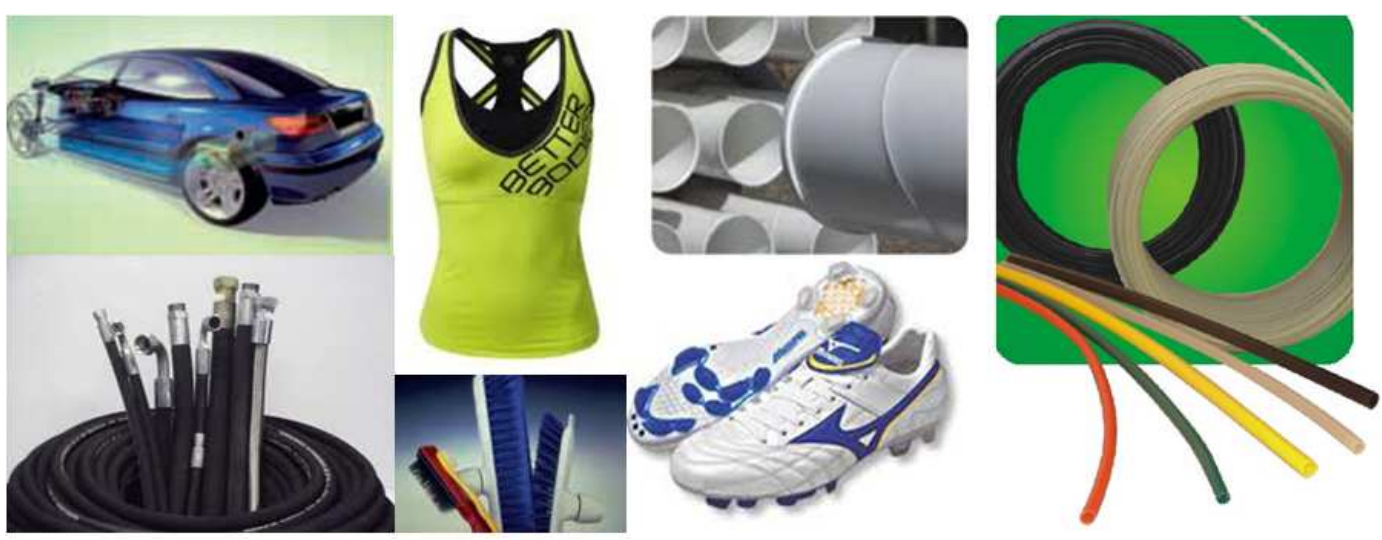

Figura 5: Exemplos de aplicações da poliamida 11.

\subsubsection{Nanocompósitos}

O estudo de nanocompósitos com matriz em Nylon 11 vem ganhando um importante espaço, principalmente devido à necessidade de melhoria das propriedades térmicas e mecânicas do nylon. Lao et al. [7] estudaram o comportamento de nanocompósitos à base de nylon 11 com três diferentes tipos de cargas (nanoargilas, nanofibras de carbono e nanosílicas) e relataram uma melhora nas propriedades térmicas e em sua inflamabilidade. Embora tenham utilizado o microscópio eletrônico de varredura (MEV) e observado uma boa dispersão das nanoargilas e nanofibras de carbono, as imagens não foram reportadas para que tal afirmação fosse comprovada.

Nanocompósitos de nylon 11 reforçado por nanoargilas também foram reportados por Liu et al. [10]. A amostra foi preparada pelo processamento no estado fundido e apesar de várias concentrações terem sido testadas, foi observada uma melhora nas propriedades térmicas e mecânicas apenas com a adição de concentrações menores que 4\%p de carga, à exceção do módulo de elasticidade, onde houve um aumento mesmo com $8 \%$ p de carga. Para avaliar o comportamento térmico foi utilizada a balança termogravimétrica (TGA) e para avaliar as propriedades mecânicas, a análise dínamo-mecânica (DMA) e ensaios de tração foram realizados. 
De acordo com os resultados apresentados pelo TGA, houve um aumento de aproximadamente $20^{\circ} \mathrm{C}$ na temperatura de decomposição para um teor de nanocargas de 4\%p. Em contrapartida, para valores acima de 4\%p, a temperatura de decomposição diminui cerca de 5 a $10^{\circ} \mathrm{C}$ (figura 6).

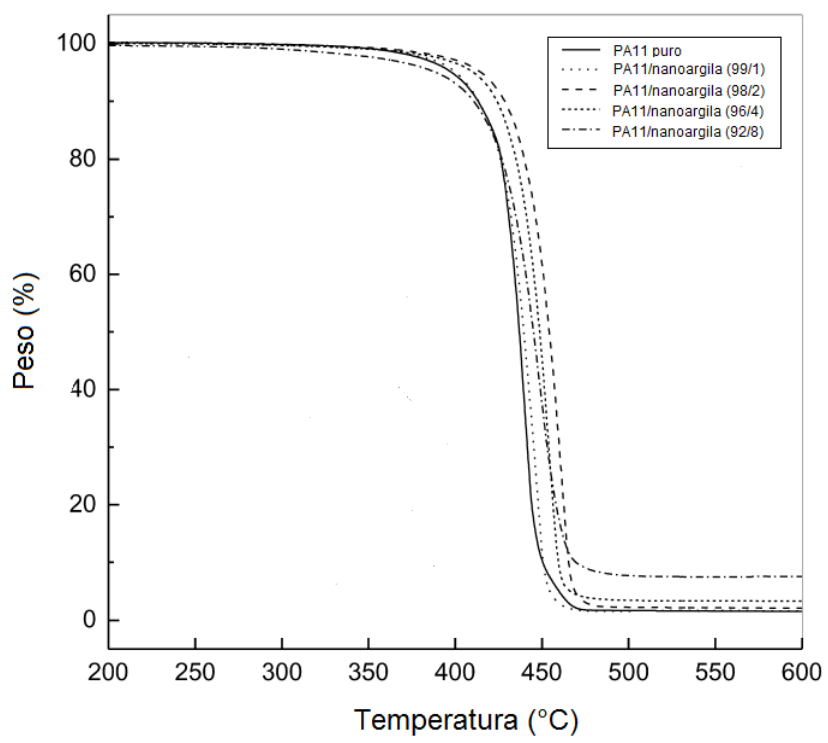

Figura 6: Resultados do TGA da PA11 pura e dos nanocompósitos com diversas concentrações [10].

A figura 7 (a) mostra o DMA realizado para as diversas amostras onde o módulo de armazenamento E’ foi avaliado. Pode-se notar que a partir de 4\%p de carga, o módulo é muito maior do que o da PA11 pura. Liu atribui esse resultado a uma boa dispersão efetuada nesse trabalho. Já a figura 7 (b) mostra as curvas de tensão e deformação geradas a partir do ensaio de tração. A partir do gráfico, o módulo de Young foi calculado e revelou uma melhora significativa para concentrações menores que $4 \%$ p. 

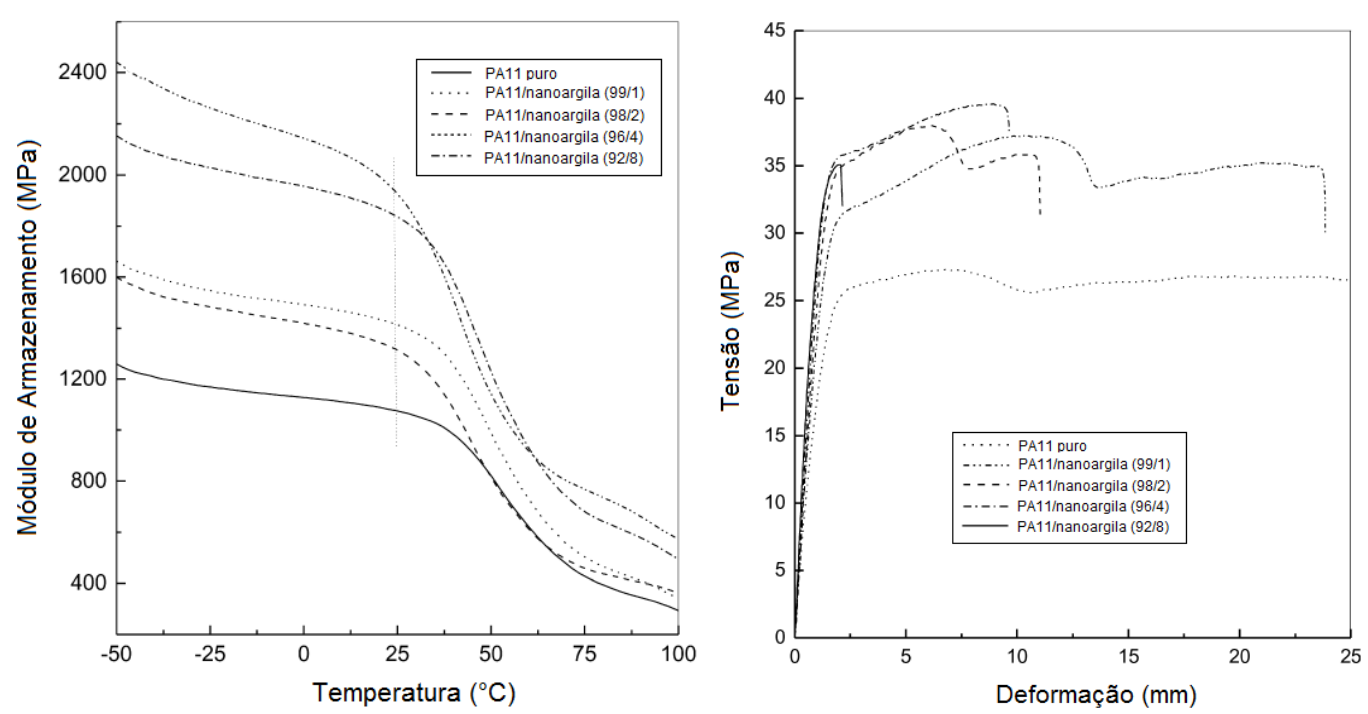

Figura 7: Resultados da PA11 pura e dos nanocompósitos com diversas concentrações (a) DMA; (b) Ensaio de tração [10].

\subsection{Nanocompósitos com matriz polimérica e carga de nanomateriais 1D baseados em $\mathrm{TiO}_{2}$}

O Titânio é um elemento encontrado em abundância na terra e sua forma mais comum é o $\mathrm{TiO}_{2}$. Ele possui diversas estruturas como o rutilo e o anatásio, ambas tetragonais, e a bruquita, que apresenta estrutura ortorrômbica. Em geral a bruquita é instável e de baixo interesse, já o rutilo é formado em temperaturas elevadas, maiores que $1000^{\circ} \mathrm{C}$ e o anatásio é formado a partir de temperaturas em torno de $450^{\circ} \mathrm{C}$ [37]. $\mathrm{O} \mathrm{TiO}_{2}$ é muito utilizado na indústria, onde atua como aditivos para plásticos, pigmento branco, eletrodo para baterias de lítio, células solares, sensor de gás, entre outros.

Os nanotubos de titanato (TTNT) ganharam particular interesse a partir do desenvolvimento da síntese hidrotérmica alcalina (figura 8), por ser um método simples de fabricação, onde não há a necessidade de moldes, baixo custo e devido ao fato de se obter nanotubos com diâmetros em torno de $10 \mathrm{~nm}$. Esse método descrito pela primeira vez por Kasuga et al $[17,18]$ se tornou o principal meio de fabricação dos nanotubos de titanato. Entretanto, muitos outros métodos também 
foram documentados, como pirólise, deposição química a vapor, deposição física a vapor [38], oxidação anódica [19] entre outros.

A síntese hidrotérmica alcalina de Kasuga ocorre por meio da adição do $\mathrm{TiO}_{2}$, que pode estar na forma de anatásio, rutilo, bruquita ou uma mistura destes, em uma solução concentrada de $\mathrm{NaOH}$ (10M), em uma autoclave, a temperaturas entre $100^{\circ} \mathrm{C}$ e $200^{\circ} \mathrm{C}$. Em seguida o material é lavado com água e/ou $\mathrm{HCl}(0,1 \mathrm{M})$. Dependendo das condições de síntese (como, por exemplo, temperatura e granulometria do $\mathrm{TiO}_{2}$ precursor) podem ser sintetizados nanotubos ou nanofitas.

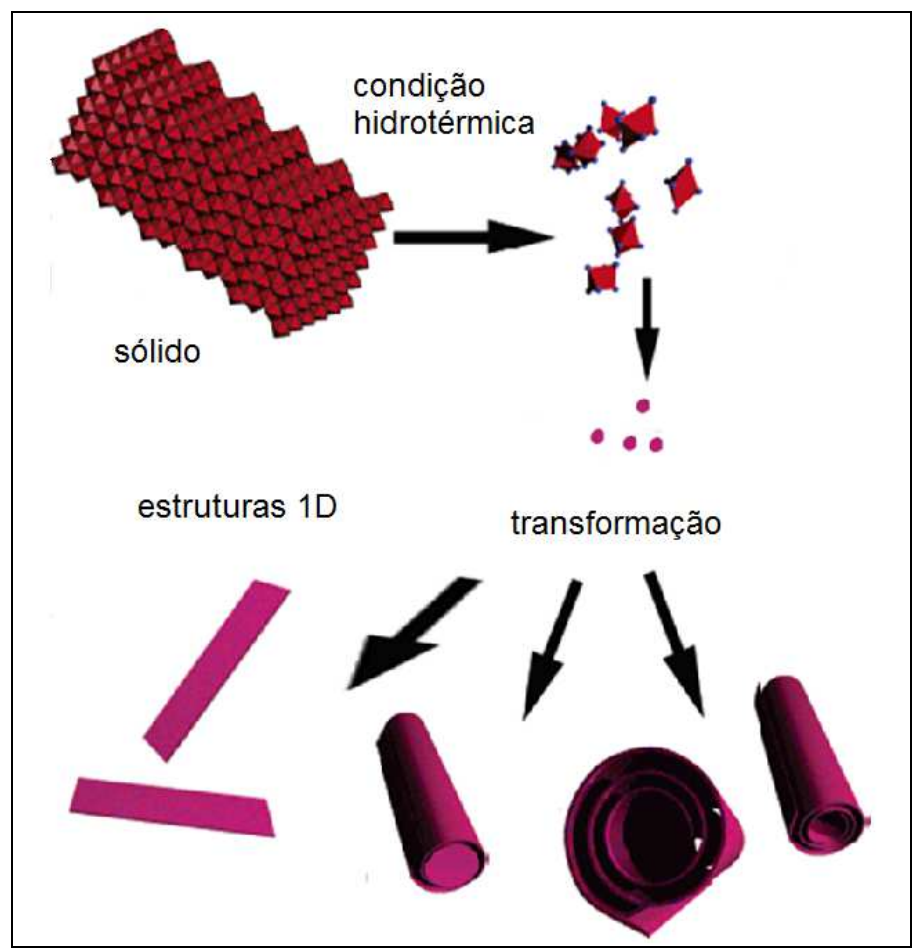

Figura 8 - Esquema da transformação das nanoestruturas através do método hidrotérmico alcalino.

Muitas estruturas cristalinas e composições foram propostas para descrever a estrutura dos nanotubos e nanofitas sintetizados pelo método de Kasuga, entre elas, $\mathrm{TiO}_{2}$-anatásio [18,39-42], Trititanatos $\mathrm{H}_{2} \mathrm{Ti}_{3} \mathrm{O}_{7}$ [43-47], $\mathrm{H}_{2} \mathrm{Ti}_{3} \mathrm{O}_{7} \cdot \mathrm{nH}_{2} \mathrm{O}$ [48], $\mathrm{Na}_{\mathrm{x}} \mathrm{H}_{2-\mathrm{x}} \mathrm{Ti}_{3} \mathrm{O}_{7}$ [49-51], Tetratitanatos $\mathrm{H}_{2} \mathrm{Ti}_{4} \mathrm{O}_{9} \cdot \mathrm{H}_{2} \mathrm{O}$ [52] e Lepidocrocita [53-54]. Entretanto, a estrutura de trititanato $\mathrm{Na}_{\mathrm{x}} \mathrm{H}_{2-\mathrm{x}} \mathrm{Ti}_{3} \mathrm{O}_{7}$ é a mais aceita entre os autores dos trabalhos mais recentes. A concentração de $\mathrm{Na}(\mathrm{x})$ dependerá do processo de 
lavagem, onde ocorre a troca dos ions $\mathrm{Na}^{+}$pelos $\mathrm{H}^{+}$localizados entre as camadas da estrutura cristalina.

No presente trabalho foram utilizados TTNTs (figura 9) com estrutura de trititanatos $\left(\mathrm{Na}_{0.1} \mathrm{H}_{1.9} \mathrm{Ti}_{3} \mathrm{O}_{7} .0 .1 \mathrm{H}_{2} \mathrm{O}\right)$ (Figura 10) que foram obtidos pela síntese hidrotérmica utilizando como precursor $\mathrm{TiO}_{2}$ com estrutura cristalina de anatásio. Segundo Morgado et al [55] a estrutura de trititanato desses nanotubos permanece sem alterações até temperaturas em torno de $200^{\circ} \mathrm{C}$. A partir daí, ela inicia uma transformação para uma estrutura de hexatitanato, que só é completamente finalizada em temperaturas acima de $250^{\circ} \mathrm{C}$.

Dentre suas principais aplicações podemos citar os dispositivos semicondutores, células fotovoltaicas, fotocatalisadores, entre outros [56].
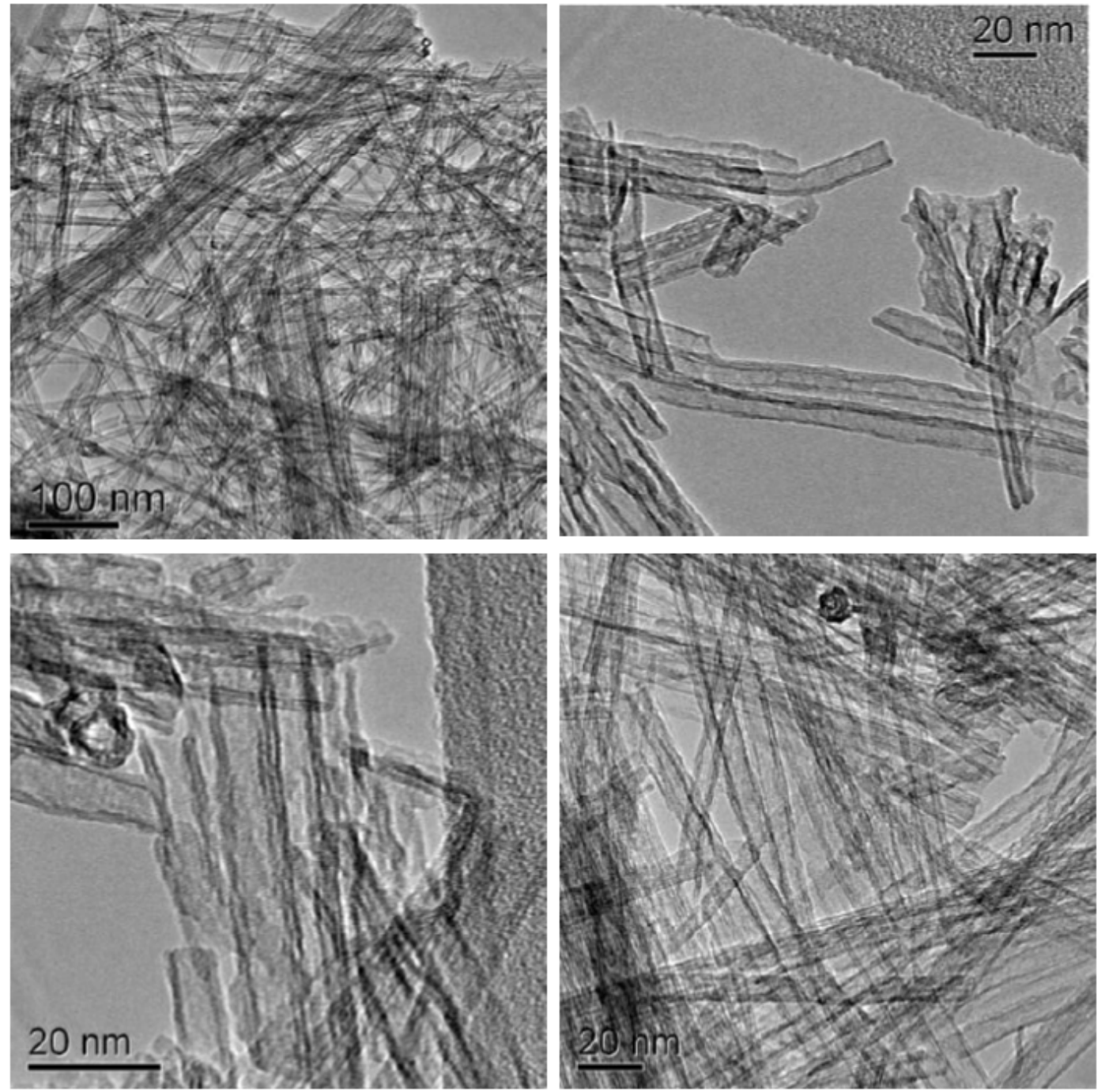

Figura 9 - Imagens de MET dos nanotubos de titanato utilizados neste trabalho [57]. 


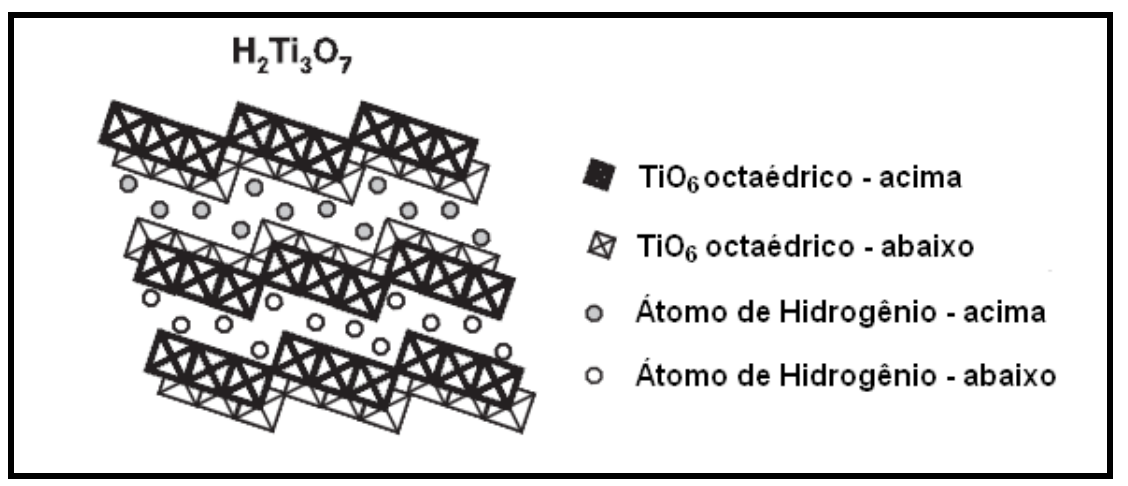

Figura 10 - Estrutura do trititanato [55].

As propriedades mecânicas das cargas também são um fator crucial para a sua utilização em nanocompósitos. Humar et al [58] mediram tais propriedades em nanofitas de titanato através do método de dobramento em três pontos, utilizando um microscópio de força atômica, e o módulo de Young encontrado foi de aproximadamente $260 \pm 55 \mathrm{GPa}$, o que comprova suas excelentes propriedades elásticas. Este artigo foi a motivação para o desenvolvimento de nanocompósitos poliméricos com nanoestruturas de titanato no presente trabalho.

Valores para o módulo de Young de nanotubos de titanato também foram reportados [59]. Com valores de aproximadamente 230GPa, os nanotubos também figuram como um bom elemento de reforço para matrizes poliméricas.

Alguns nanocompósitos de matriz polimérica com cargas de nanotubos e nanofitas de titanato têm sido reportados na literatura. Umek et al [8] produziram nanocompósitos de poliestireno reforçados com $1 \%$ p de nanoestruturas de titanato 1D (nanotubos e nanofitas) a partir de um processo de extrusão e mediu suas propriedades mecânicas. Para o caso dos nanocompósitos com nanofitas, houve um aumento do módulo de Young. Entretanto o mesmo não pode ser observado para os nanocompósitos reforçados por nanotubos, onde houve um decréscimo do módulo. Esse resultado está diretamente associado à dispersão da carga na matriz. Como os nanotubos possuem uma tendência à aglomeração, a necessidade de uma boa dispersão se torna indispensável. As microestruturas foram analisadas através de imagens de MEV e comprovaram a aglomeração dos nanotubos na matriz.

Cheng et al [60] produziram polianilinas reforçadas por nanotubos de titanato por polimerização in situ. Kralova et al [61] fabricaram poliamida 6 reforçada por $5 \%$ p de nanotubos de titanato, onde o módulo de elasticidade foi 
avaliado através do DMA e revelou um aumento de $35 \%$ quando comparado à poliamida 6 pura. Filmes de poliestireno com cargas entre 0 e $1 \%$ p de nanotubos de titanato funcionalizados foram fabricados por Byrne et al [59]. Foi observado um aumento de $18 \%$ no módulo de Young para uma fração volumétrica de nanotubos de $3,8 \times 10^{-5}$.

\subsection{Nanocompósitos com matriz polimérica e carga de nanopartículas de $\mathrm{TiO}_{2}$}

Como já descrito nesta revisão bibliográfica, o $\mathrm{TiO}_{2}$ é encontrado na natureza sob diversas estruturas cristalinas, sendo as principais o rutilo, o anatásio e a bruquita.

Nanopartículas embebidas em uma matriz polimérica ganharam particular interesse devido à melhora nas propriedades mecânicas, elétricas, ópticas e magnéticas, entre outras, apresentadas pelos nanocompósitos quando comparados à matriz polimérica pura. Essa melhora nas propriedades se deve ao fato das nanopartículas possuírem uma grande área superficial, o que altera o comportamento do material através das interações interfaciais [13].

Muito já foi reportado na literatura comprovando a eficiência das nanopartículas inseridas em matriz polimérica. Entretanto, essa melhora só se torna possível com uma boa dispersão do material na matriz. Chatterjee et al [13] fabricaram nanocompósitos com 0,5 a 2\%p de nanopartículas de $\mathrm{TiO}_{2}$ em uma matriz de epóxi. Suas nanopartículas possuíam tamanho de 5nm, módulo de elasticidade entre 200 a $300 \mathrm{GPa}$ e resistência à tração de $350 \mathrm{MPa}$. Com uma dispersão bem sucedida, os nanocompósitos apresentaram uma melhora significativa nas propriedades térmicas e mecânicas com apenas 1\%p de carga.

Poliuretano reforçado por $1 \%$ p de nanopartículas de $\mathrm{TiO}_{2}$ tiveram suas propriedades térmicas e mecânicas avaliadas por Saha et al [9]. Para tal, foi utilizada a TGA e análises de tensão, compressão e flexão. Um pequeno aumento foi observado tanto na temperatura de decomposição do nanocompósito quanto nas propriedades mecânicas. 
Ohno et al [62] analisaram através do microscópio eletrônico de transmissão (MET) a morfologia das nanopartículas comerciais do tipo P-25, que tem como característica uma mistura de fases entre anatásio e rutilo, avaliando ambas as fases (Figura 11-a e 11-b).

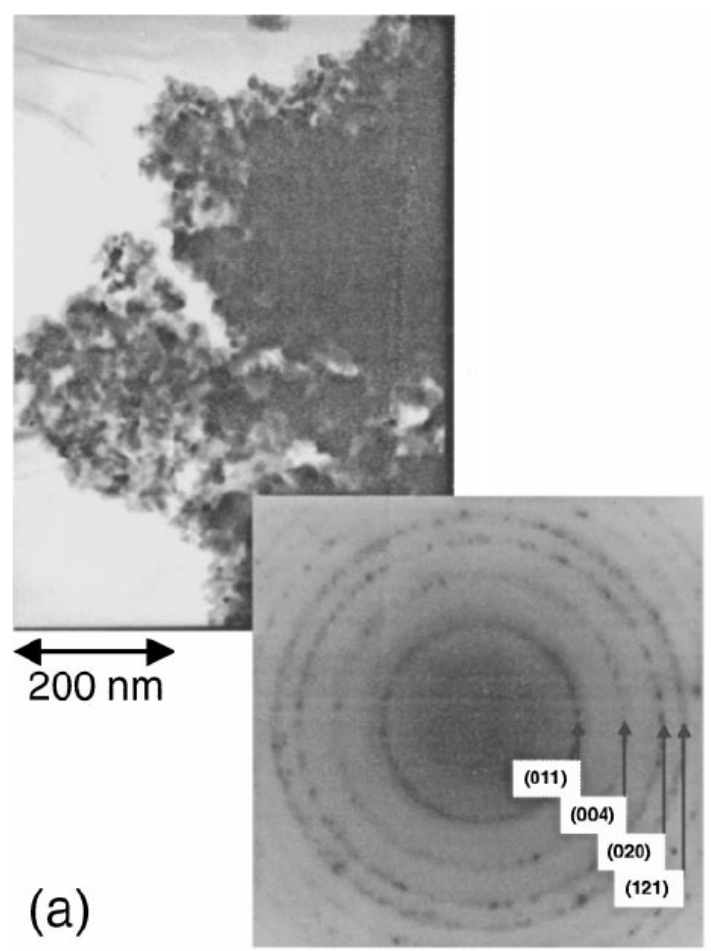

(b)

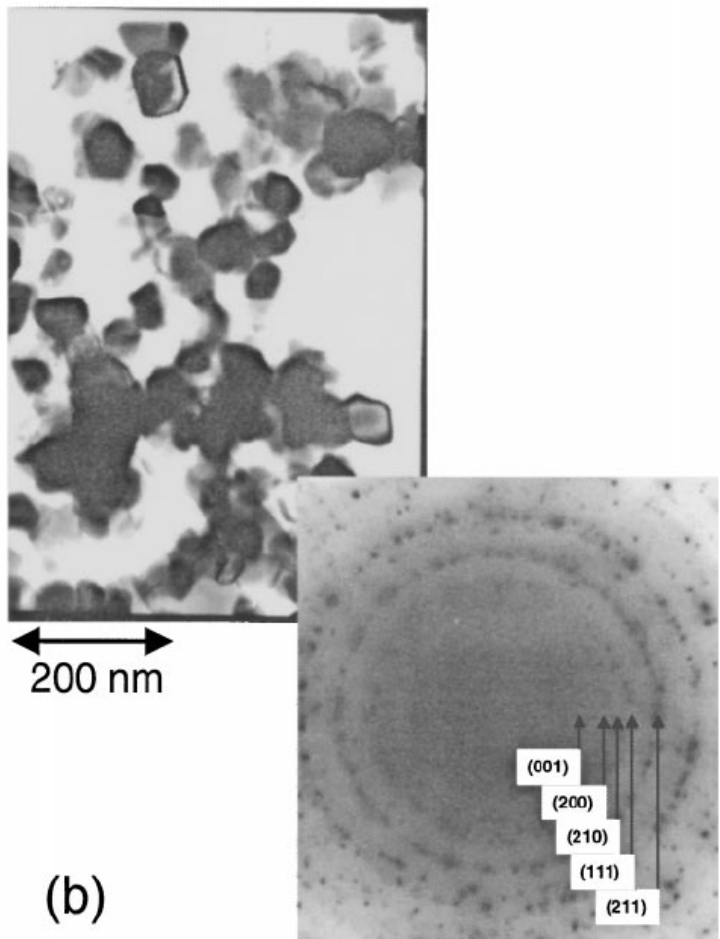

(211)

Figura 11 - Imagens de MET e difração de elétrons do P-25 nas regiões (a) da fase anátsio e (b) na fase rutilo [62].

Muitos pesquisadores utilizaram as nanopartículas de $\mathrm{TiO}_{2}$ do tipo $\mathrm{P} 25$ para a fabricação de nanocompósitos. Recentemente foi reportado na literatura um trabalho contendo nanopartículas de $\mathrm{TiO}_{2}$ em uma matriz de poliamida 11, na forma de fibras, revestidos por uma superfície de polipropileno [31]. O processo realizado foi o electrospinning com o objetivo de produzir filtros. As propriedades fotocatalíticas foram avaliadas e demonstrou-se que é possível adicionar tais propriedades através do método utilizado. Zhang et al [31] utilizaram tal carga em uma matriz de poliamida 6,6. Em seu artigo esses autores comprovam que mesmo com pequenas quantidades de carga, 3,4\% p, o comportamento do polímero na 
fluência melhora consideravelmente tanto a temperatura ambiente quanto a temperaturas elevadas. Nanocompósitos em forma de membranas com $\mathrm{PA} / \mathrm{TiO}_{2}$ foram fabricados por polimerização interfacial in situ e reportados por Lee et al [14]. Com uma concentração de 5\%p de nanopartículas de $\mathrm{TiO}_{2}$ foi observada uma melhora nas propriedades mecânicas da membrana.

\subsection{Propriedades mecânicas dos polímeros}

Para ter um bom entendimento sobre os polímeros, é muito importante conhecer seus mecanismos de deformação e consequentemente suas características mecânicas. Parâmetros como módulo de elasticidade (E), resistência à tração, ao impacto e à fadiga são algumas das medidas realizadas para se conhecer melhor tais características.

Tratando-se de polímeros, três diferentes tipos de comportamento podem ser observados em uma típica curva tensão-deformação (figura 12). A curva A ilustra o comportamento de um polímero frágil, a curva B ilustra o comportamento de um material plástico enquanto a curva C ilustra o comportamento de um elastômero [63]. O comportamento do Nylon 11 utilizado neste trabalho, à temperatura ambiente, se assemelha ao de um plástico (curva B). 


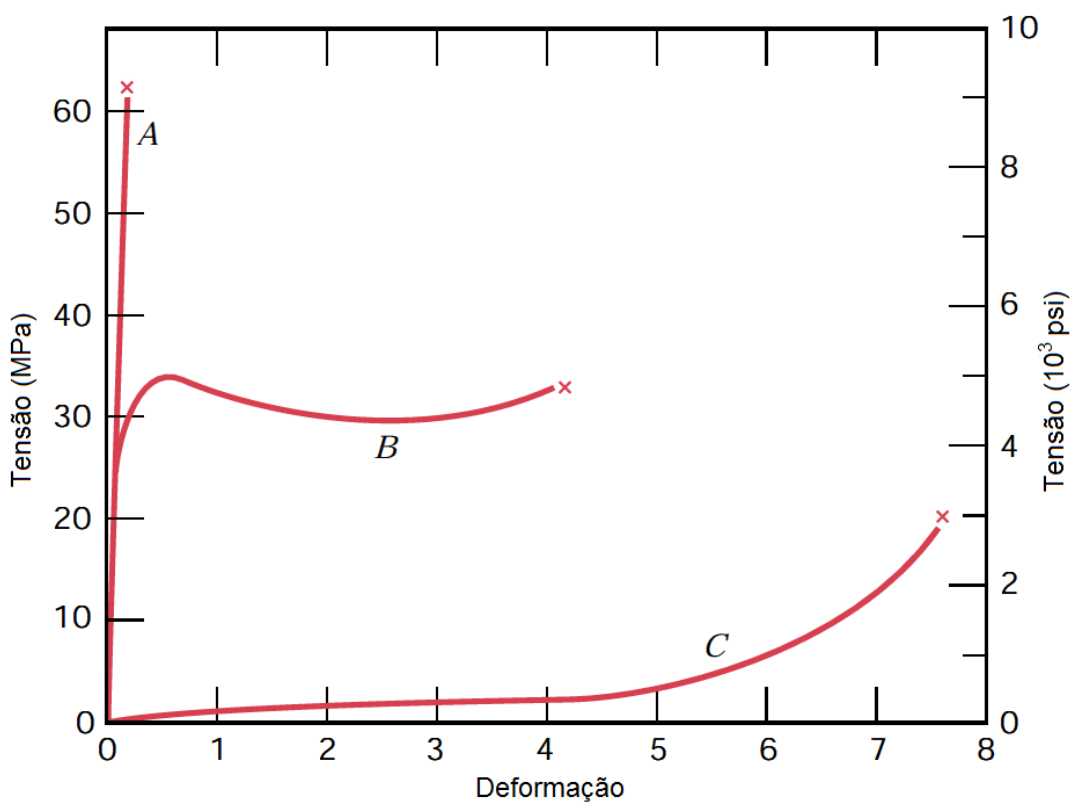

Figura 12 - 3 tipos de curva tensão x deformação para polímeros. [63].

Alguns fatores influenciam diretamente as propriedades mecânicas dos polímeros, tal como o aumento do grau de cristalinidade, que gera um aumento do módulo de elasticidade e do limite de resistência à tração. Isso ocorre porque a área cristalina onde as cadeias moleculares estão densamente empilhadas, em um arranjo ordenado e paralelo, é formada por ligações primárias e secundárias que inibem o movimento da cadeia polimérica. Já numa região amorfa, o desalinhamento das cadeias diminui o número de ligações, o que acarreta numa diminuição das forças intermoleculares.

Outros fatores importantes que alteram as propriedades dos polímeros são a temperatura e a taxa de deformação. $\mathrm{O}$ aumento da temperatura gera uma diminuição do $\mathrm{E}$ e do limite de resistência à tração, entretanto há uma melhora na ductilidade.

A tabela 1 mostra algumas propriedades típicas dos polímeros industriais mais utilizados [64]. 


\begin{tabular}{|c|c|c|c|c|c|}
\hline \multirow{2}{*}{ Polímero } & \multicolumn{2}{|c|}{$\begin{array}{c}\text { Transição Térmica } \\
\left({ }^{\circ} \mathrm{C}\right)\end{array}$} & \multicolumn{3}{|c|}{ Propriedades Típicas } \\
\cline { 2 - 6 } & $\begin{array}{c}\text { Vítrea } \\
\left(\mathrm{T}_{\mathrm{g}}\right)\end{array}$ & $\begin{array}{c}\text { Fusão } \\
\left(\mathrm{T}_{\mathrm{m}}\right)\end{array}$ & $\begin{array}{c}\text { Resistência à } \\
\text { tração }(\mathrm{MPa})\end{array}$ & $\begin{array}{c}\text { Alongamento } \\
(\%)\end{array}$ & $\begin{array}{c}\text { Módulo de } \\
\text { Young (MPa) }\end{array}$ \\
\hline $\begin{array}{c}\text { Polietileno de } \\
\text { Baixa Densidade }\end{array}$ & -30 & 120 & 16 & 650 & 250 \\
\hline Polipropileno & $4-12$ & 165 & 55 & 160 & 1210 \\
\hline Poliestireno & 100 & 235 & 23 & 3 & 3100 \\
\hline Poli (metacrilato \\
de metila)
\end{tabular}

* Os valores para a Polimida 11 foram retirados do catálogo da Rilsan ${ }^{\circledR}$.

Tabela 1 - Propriedades típicas dos polímeros industriais mais utilizados. [64].

\subsubsection{Ensaio de Tração}

O ensaio de tração consiste na aplicação de uma força uniaxial em um corpo de prova, onde a amostra sob tração é deformada até a sua ruptura. Durante o ensaio, a amostra passa por dois regimes de deformação: elástico e plástico. A deformação elástica é um processo reversível enquanto que a deformação plástica é irreversível.

A deformação elástica que ocorre a cerca de $0,1 \%$ de deformação é mais evidente quando estes materiais são altamente cristalinos ou estão abaixo da temperatura de transição vítrea (Tg). Na deformação elástica o comportamento do material se assemelha ao de uma mola, portanto a lei de Hooke (deformação é 
proporcional à força aplicada) pode ser considerada para a maioria dos polímeros. Nessa região, a curva apresenta um comportamento elástico linear, e a sua inclinação, ou coeficiente angular é o módulo de Young ou módulo de elasticidade do material.

A deformação plástica é uma deformação permanente, dependente do tempo e ocorre por deslizamento das cadeias. Após o limite de escoamento há uma significativa redução da seção transversal até que ocorra a ruptura do material.

O resultado do ensaio de tração é uma curva tensão $X$ deformação onde pode-se verificar os valores de tensão de ruptura, tensão de escoamento, \% de deformação, coeficiente de encruamento, entre outros dados. O coeficiente de encruamento é uma medida da plasticidade do material e pode ser obtida através dos valores compreendidos entre a tensão de escoamento e a tensão de resistência. Esses valores são recalculados em termos de tensão e deformação verdadeira através da equação de Hollomon onde k é a constante plástica de resistência e n o coeficiente de encruamento.

$$
\sigma_{v}=k \cdot \varepsilon_{v}^{n}
$$

Para calcular o coeficiente de encruamento, a equação acima é linearizada e o coeficiente de ecruamento pode ser obtido através do coeficiente angular da reta.

\section{$\ln \sigma_{v}=\ln k+n \ln \varepsilon_{v}$}


3.

\section{Objetivo}

O objetivo deste trabalho consiste em produzir compósitos de matriz polimérica (poliamida 11) com cargas em escala nanométricas (nanotubos de titanato e nanopartículas de $\mathrm{TiO}_{2}$ ) como reforço e avaliar suas propriedades mecânicas e térmicas. 
4.

\section{Materiais e Métodos}

\subsection{Materiais}

No presente trabalho foram produzidos nanocompósitos à base de nylon 11 reforçados por cargas de nanopartículas de $\mathrm{TiO}_{2}$ e nanotubos de titanato. As nanopartículas utilizadas são comerciais do tipo P25 e possuem uma superfície específica de $50 \mathrm{~m}^{2} \mathrm{~g}^{-1}$. Esse tipo de partícula é bastante utilizado em pesquisas devido as suas propriedades fotocatalisadoras. O material é produzido em fogo através da hidrólise do $\mathrm{TiCl}_{4}$ e a transformação em $\mathrm{TiO}_{2}$ ocorre rapidamente em alta temperatura. Este processo permite obter um produto com alta área superficial e uma mistura de fases (anatásio + rutilo) [65].

Os materiais utilizados foram:

- Nylon 11 - Material comercial adquirido na NZCooperpolymer na forma de pellets.

- Nanotubos de titanato - Trititanatos nanotubulares (TTNT) produzidos pelo método descrito por Abreu [57] em sua dissertação de mestrado e já reportado nessa dissertação.

- Nanopartículas de $\mathrm{TiO}_{2}$ - Do tipo comercial Degusa P-25 com 70\% de anatásio e $30 \%$ de rutilo em sua composição.

\subsection{Método de fabricação dos nanocompósitos}

A fabricação dos nanocompósitos foi desenvolvida em diversas etapas. $\mathrm{O}$ diagrama de blocos representado na figura 13 mostra as etapas percorridas até o estágio final das caracterizações. 


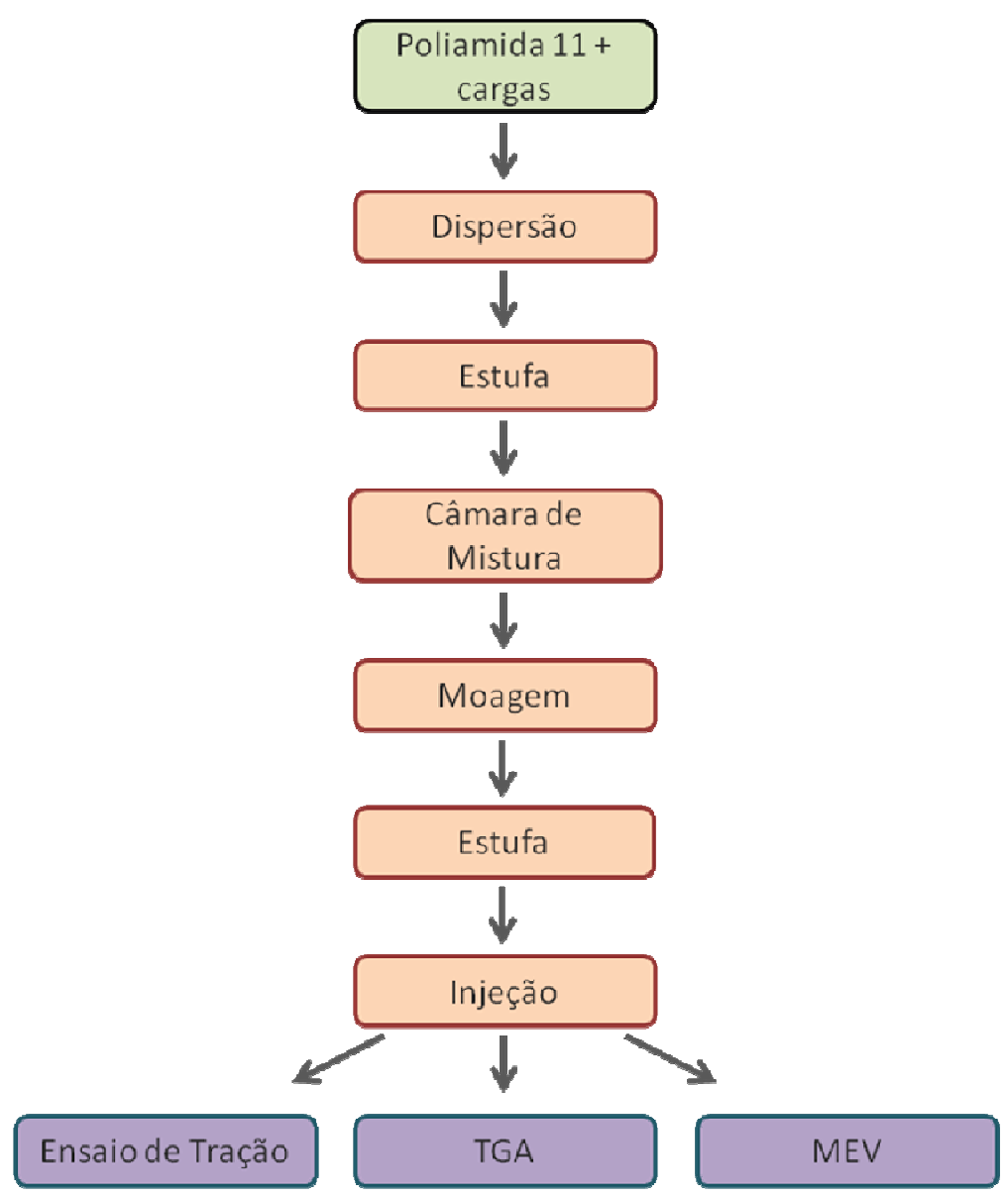

Figura 13 - Diagrama de blocos das etapas do preparo e caracterização dos nanocompósitos.

\subsubsection{Poliamida 11}

No intuito de avaliar se a etapa da câmara de mistura afeta as propriedades da poliamida, duas amostras diferentes de poliamida pura foram preparadas. A primeira, denominada $\mathrm{A} 0$, não passou pela câmara de mistura e nem pela moagem e os pellets foram diretamente para a injetora para fabricação dos corpos de prova. A segunda, denominada Ap, passou pela câmara de mistura e pela moagem e em seguida foi injetada. 


\subsubsection{Fabricação dos nanocompósitos}

O primeiro passo para a fabricação dos nanocompósitos foi a definição da porcentagem de carga que seria utilizada em cada amostra. Para os nanocompósitos reforçados por nanopartículas de $\mathrm{TiO}_{2}$, foram fabricados três diferentes tipos contendo $1 \%$ p, 3\%p e 5\%p de carga e para os reforçados por nanotubos de titanato, apenas a concentração de $1 \%$ p de carga foi fabricada. As amostras foram nomeadas de acordo com a tabela 2.

\begin{tabular}{cc}
\hline Amostra & Carga \\
\hline $\mathrm{A} 0$ & 0 \\
$\mathrm{Ap}$ & 0 \\
\hline $\mathrm{A} 1$ & $1 \% \mathrm{p} \mathrm{TiO}_{2}$ \\
\hline $\mathrm{A} 2$ & $3 \% \mathrm{p} \mathrm{TiO}_{2}$ \\
\hline $\mathrm{A} 3$ & $5 \% \mathrm{p} \mathrm{TiO}_{2}$ \\
\hline $\mathrm{A} 4$ & $1 \% \mathrm{p} \mathrm{TTNT}$ \\
\hline
\end{tabular}

Tabela 2 - Nomenclatura adotada para as amostras de acordo com o percentual de carga.

Na primeira etapa, a poliamida 11 na forma de pellets foi colocada em um pequeno recipiente plástico juntamente com a porcentagem de carga especificada. Logo, quatro recipientes diferentes foram preparados contendo a poliamida 11 juntamente com suas respectivas composições de nanopartículas de $\mathrm{TiO}_{2}$ e de nanotubos de titanato. Esses recipientes foram introduzidos num pequeno misturador cerâmico (figura 14) que ficou em rotação por 12 horas. Essa etapa foi feita para haver dispersão da carga na matriz, uma vez que o impacto introduzia a carga na forma de pó nos pellets de nylon 11. 

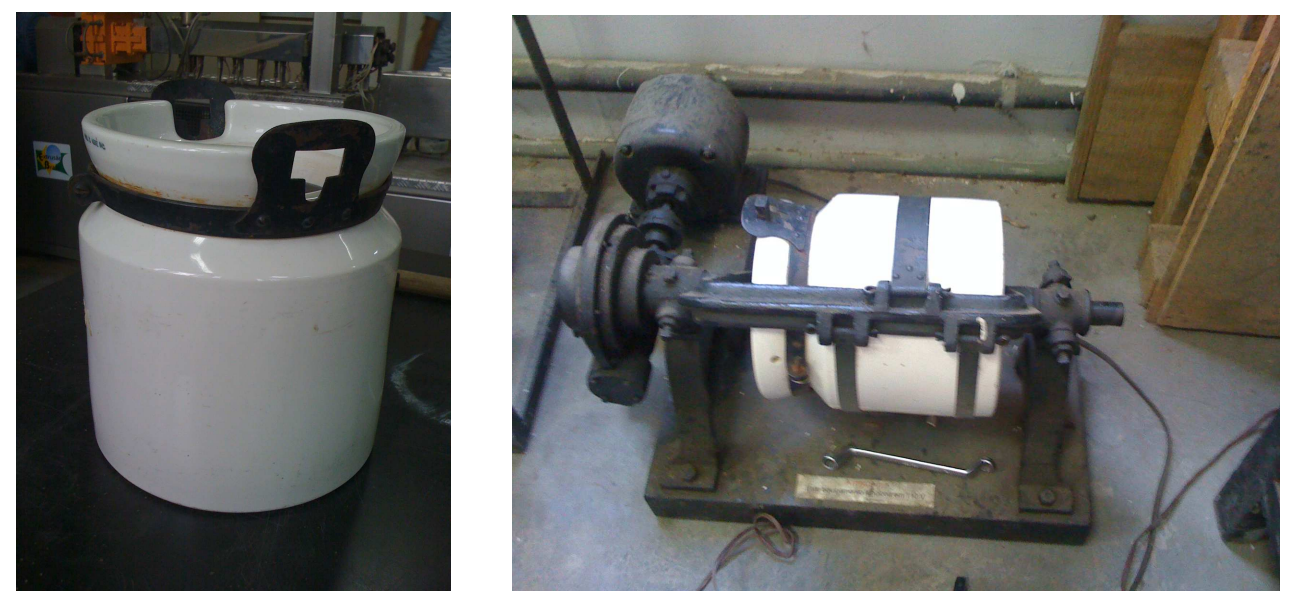

Figura 14 - Imagens do misturador utilizado na etapa de dispersão.

Após a dispersão, os 4 diferentes conjuntos foram colocados na estufa a uma temperatura de $80^{\circ} \mathrm{C}$ por 24 horas. Como as poliamidas tendem a absorver muita água, esta etapa se torna indispensável para o processo.

$\mathrm{Na}$ etapa seguinte, os conjuntos foram levados a uma câmara de mistura Rheomix 600 OS separadamente. Acoplado à câmara estava um reômetro de torque Thermo Electron Corporation, modelo Haake Polylab OS RheoDrive 4, com rotores do tipo "Roller". A velocidade dos rotores foi ajustada para $80 \mathrm{rpm}$ e a temperatura da câmara em $220^{\circ} \mathrm{C}$. O tempo total de mistura foi de 5 minutos. Os parâmetros utilizados foram baseados em experimentos anteriores descritos na literatura [66].

Todo o material preparado foi moído em um moinho de duas facas SEIBT, modelo MGHS 1,5/85 com velocidade de $1150 \mathrm{rpm}$ para que pudesse ser feita a injeção.

A etapa de injeção foi feita em uma Prensa de injeção semi-industrial, modelo Battenfeld ${ }^{\mathrm{TM}}$ Plus 35-75 35 ton, com parafuso de diâmetro de $25 \mathrm{~mm}$ e razão L/D igual a 15 e os corpos de prova obtidos seguem a norma DIN 53504 para ensaios de tração e deformação e possuem dimensões de 75 × 20 x $4 \mathrm{~mm}$ (figura 15). Os parâmetros utilizados estão descritos na tabela 3. 


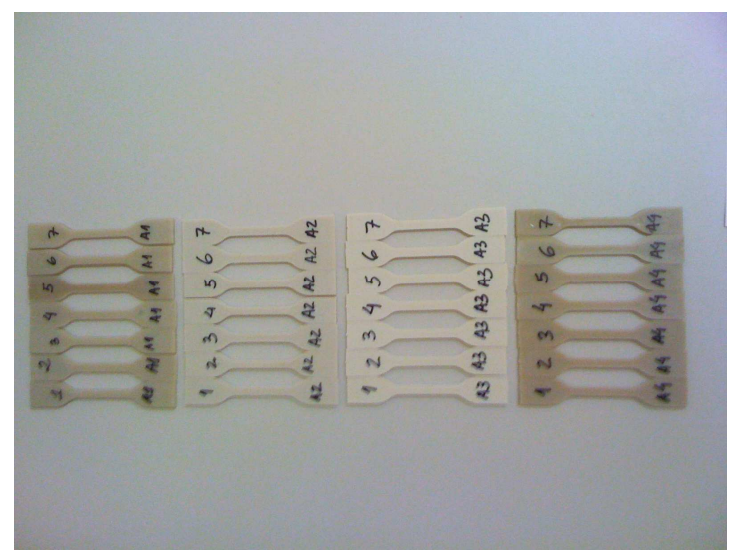

Figura 15 - Imagem dos corpos de prova feitos na etapa de injeção.

\begin{tabular}{lc}
\hline \multicolumn{2}{c}{ Parâmetros da Injeção } \\
\hline Temperatura de Injeção $\left({ }^{\circ} \mathrm{C}\right)$ & $235-245$ \\
Temperatura do Molde $\left({ }^{\circ} \mathrm{C}\right)$ & 25 \\
Pressão de Injeção (MPa) & 9 \\
Pressão de Recalque (MPa) & 4 \\
Tempo de Resfriamento (s) & 30 \\
Rotação da Rosca (rpm) & 300 \\
\hline
\end{tabular}

Tabela 3 - Parâmetros utilizados na injeção.

Todas as etapas de preparação das amostras foram realizadas no Laboratório de Tecnologia de Materiais Poliméricos (LAMAP), localizado na Divisão de Processamento e Caracterização de Materiais - Instituto Nacional de Tecnologia (INT), à exceção apenas da etapa de moagem, que foi realizada no Laboratório de Apoio Tecnológico (LAPTEC), localizado no Instituto de Macromoléculas Professora Eloísa Mano - UFRJ. 


\subsection{Técnicas de Caracterização}

\subsubsection{Microscópio eletrônico de varredura (MEV)}

O MEV da marca JEOL, modelo JSM-6510L, foi utilizado no modo SEI (elétrons secundários), com uma tensão de $20 \mathrm{kV}$, com o objetivo de avaliar a superfície de fratura dos nanocompósitos e identificar uma possível aglomeração das cargas. O modo EDS também foi utilizado para confirmar as composições presentes em uma análise qualitativa. Todas as amostras foram metalizadas com ouro. O equipamento utilizado pertence ao Laboratório de Microscopia Eletrônica (LME), do Departamento de Engenharia de Materiais (DEMa) - PUC-Rio.

\subsubsection{Ensaio de tração}

Os ensaios de tração foram realizados numa Máquina Universal de Ensaios EMIC, modelo DL-2000, para avaliar as propriedades mecânicas como módulo de elasticidade, tensão e deformação. Os corpos de prova são do tipo S2 (Figura 16) segundo a norma DIN 53504 para a realização de ensaios de resistência à tração e deformação. A carga utilizada foi de $1 \mathrm{kN}$, a velocidade de separação entre as garras de $10 \mathrm{~mm} / \mathrm{min}$ e $50 \mathrm{~mm} / \mathrm{min}$ e a temperatura do ensaio foi de $\pm 23^{\circ} \mathrm{C}$. Os resultados foram obtidos através da média de quatro corpos de prova. O equipamento utilizado pertence ao Laboratório de Tecnologia de Materiais Poliméricos (LAMAP), localizado na Divisão de Processamento e Caracterização de Materiais - Instituto Nacional de Tecnologia.

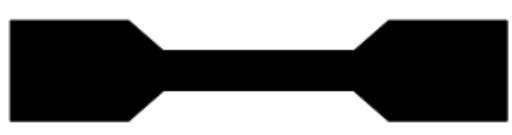

Figura 16 - Corpo de prova utilizado para o ensaio de tração 


\subsubsection{Análise Termogravimétrica (TGA)}

As análises de TGA foram feitas em um equipamento Perkin Elmer, modelo Pyris 1 e foram realizadas com o intuito de verificar a influência dos nanotubos e nanopartículas na matriz de PA11. A técnica consiste em aplicar uma variação de temperatura e analisar a mudança de massa ocorrida.

As amostras analisadas continham de 5,2 $\mathrm{mg}$ a $8,7 \mathrm{mg}$ de massa e foram pesadas em cadinho de platina e aquecidas de $25^{\circ} \mathrm{C}$ a $800^{\circ} \mathrm{C}$, sob atmosfera de nitrogênio, a uma taxa de aquecimento de $10^{\circ} \mathrm{C} / \mathrm{min}$. Esses ensaios foram realizados no LABTeR / EQ / UFRJ. 


\section{5.}

\section{Resultados e Discussão}

\subsection{Microscópio Eletrônico de Varredura (MEV)}

As análises de MEV foram realizadas nas superfícies de fratura das amostras que foram ensaiadas em tração. $\mathrm{O}$ objetivo era investigar se a etapa de dispersão foi bem sucedida o que implicaria numa não aglomeração das cargas. Entretanto, tal resultado não foi obtido, uma vez que identificamos claramente aglomerações na matriz (figura 17).
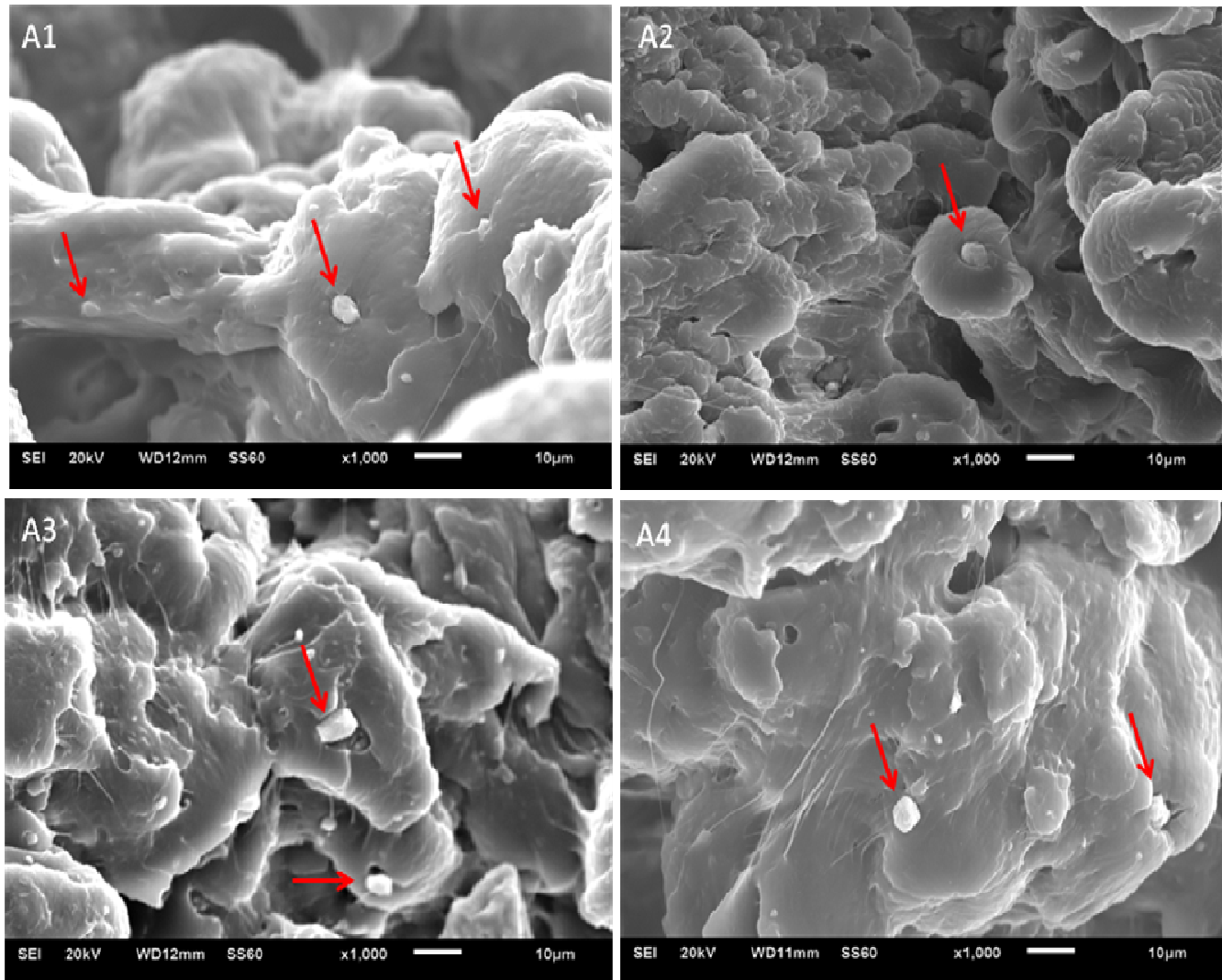

Figura 17 - Imagens de MEV das amostras A1, A2, A3 e A4 revelando a presença de cargas aglomeradas na matriz. 
Para confirmar que as aglomerações se tratavam das cargas de nanopartículas de $\mathrm{TiO}_{2}$ e nanotubos de titanato, realizamos EDS nas partículas conforme demonstrado nas figuras 18-21.
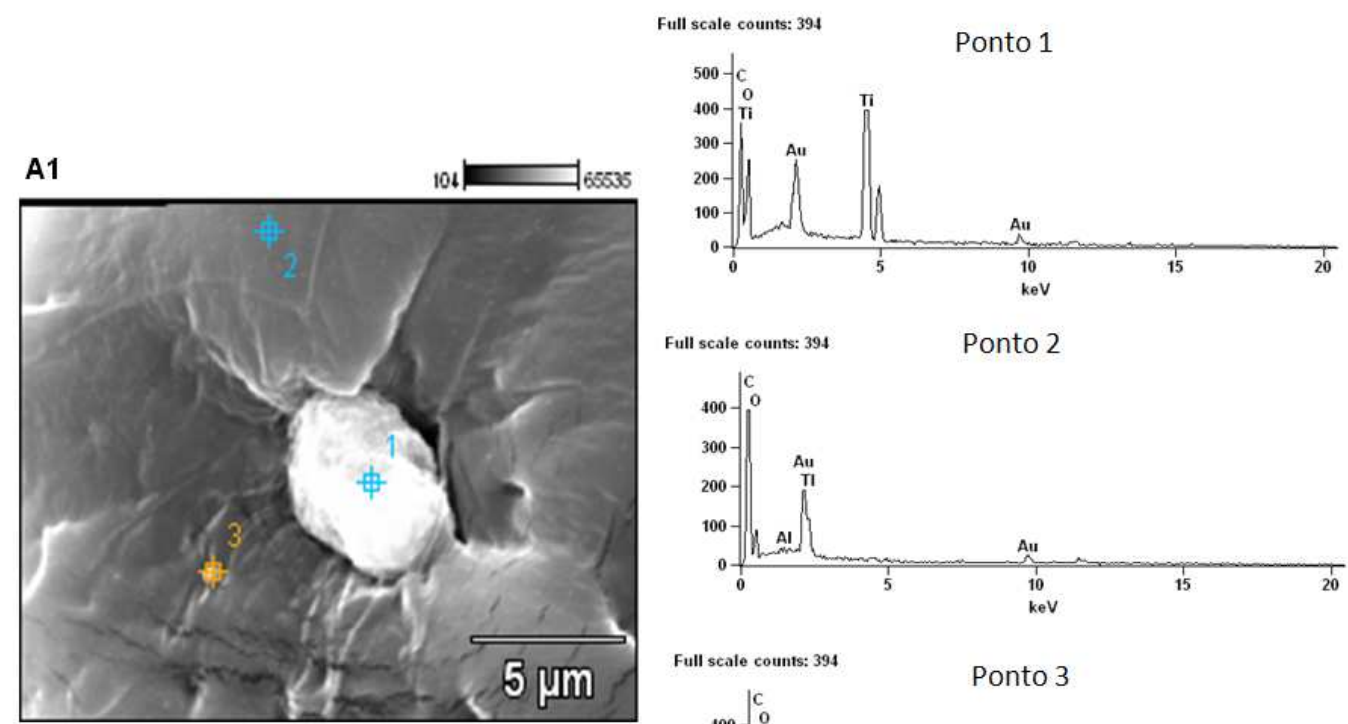

\begin{tabular}{l} 
Full scale counts: $394 \quad$ Ponto 3 \\
\hline
\end{tabular}

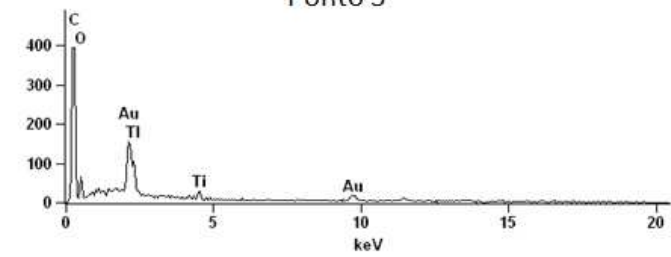

Figura 18 - Imagem de MEV e EDS na amostra A1

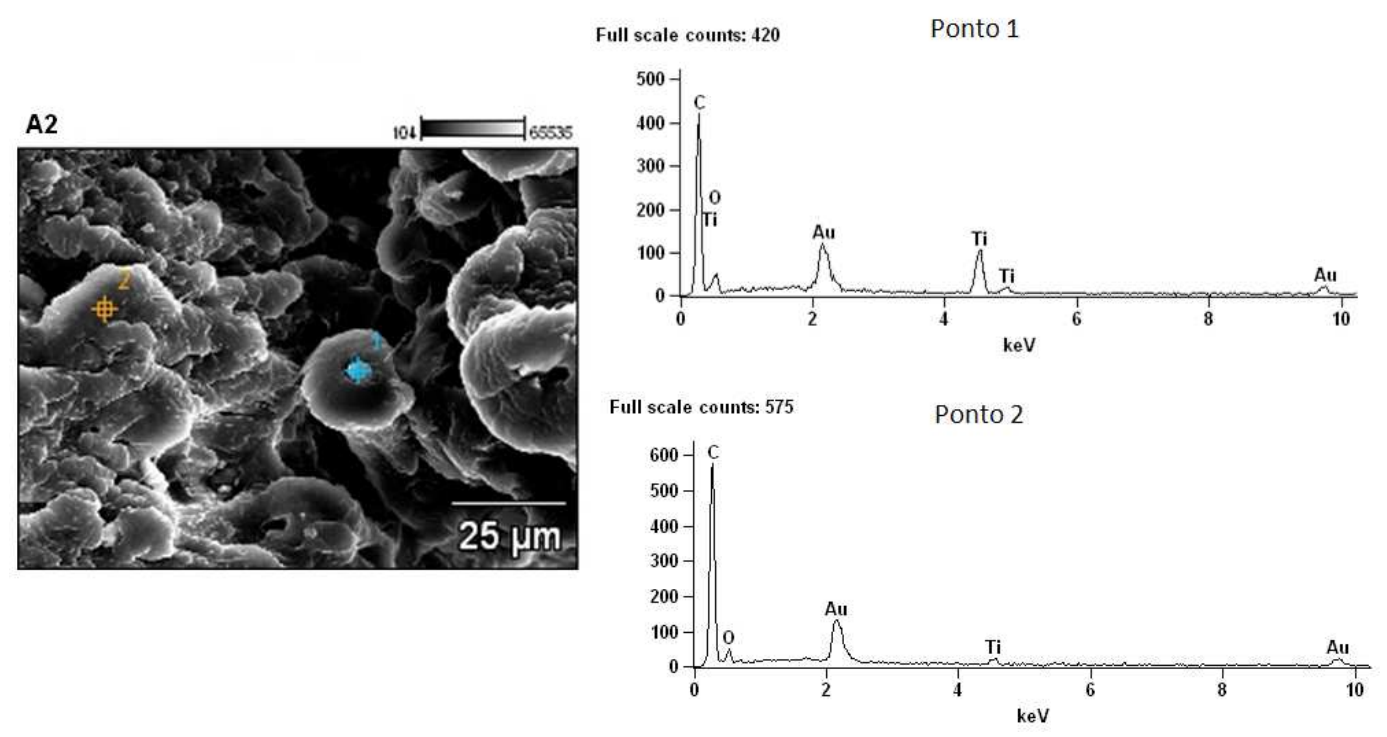

Figura 19 - Imagem de MEV e EDS na amostra A2 


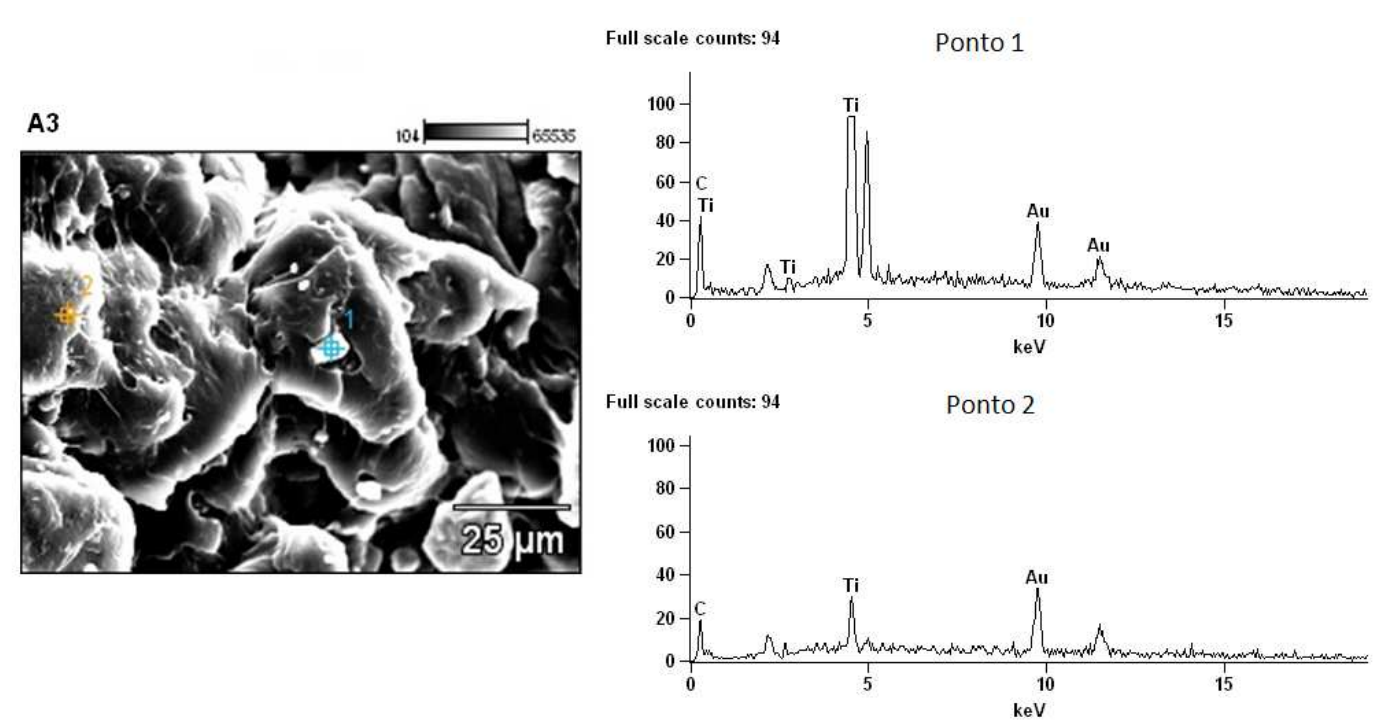

Figura 20 - Imagem de MEV e EDS na amostra A3
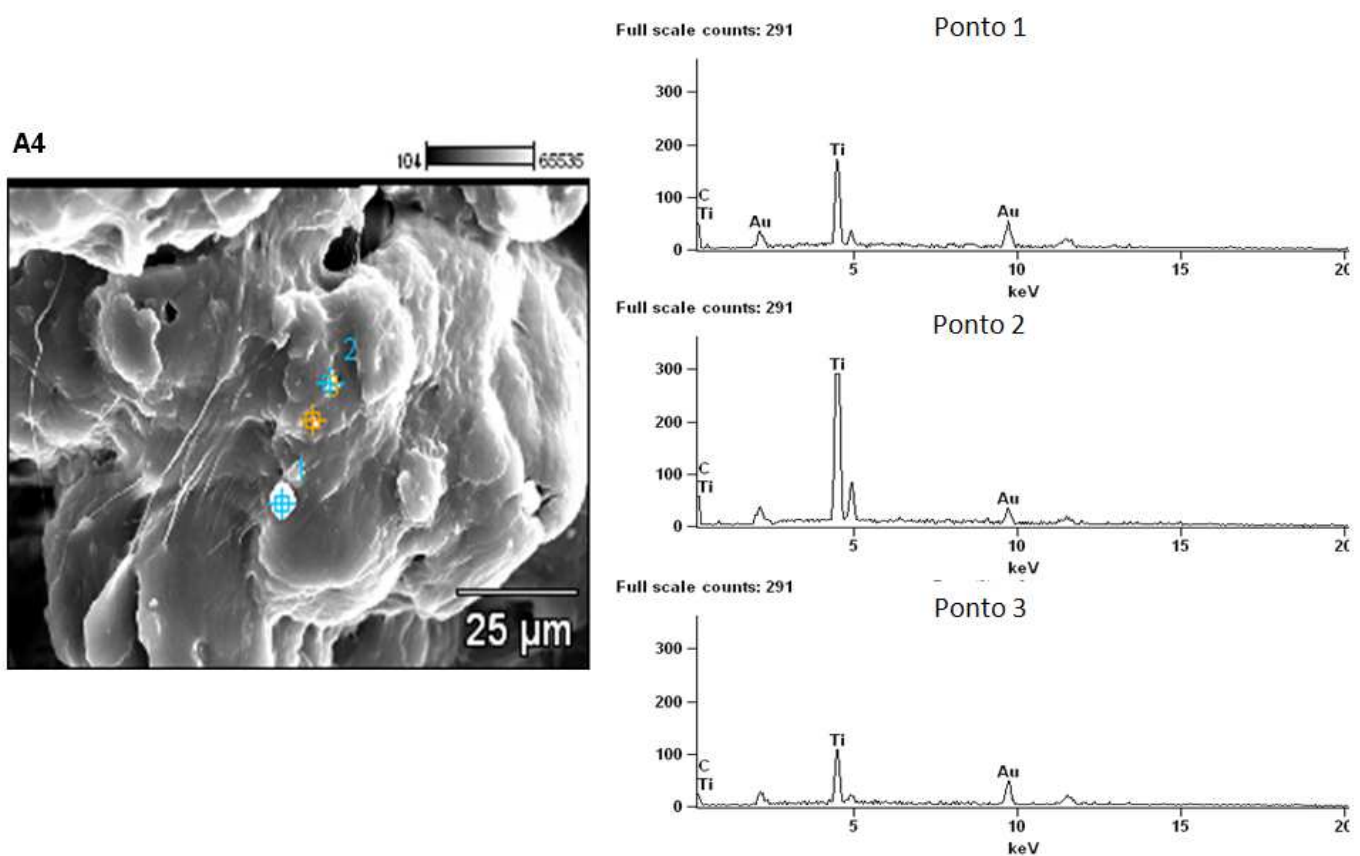

Figura 21 - Imagem de MEV e EDS na amostra A4

Devido às aglomerações, as cargas deixaram de possuir tamanho nanométrico e passaram a ter tamanhos na ordem de 3 a $4 \mu \mathrm{m}$, o que descaracteriza o material como sendo um nanocompósito. Essa aglomeração de 
cargas, influencia diretamente nas propriedades mecânicas, como será discutido mais adiante.

O problema da aglomeração de cargas vem sendo amplamente discutido na literatura [61]. Sabe-se que a etapa de dispersão é um passo vital na preparação de nanocompósitos e algumas técnicas como funcionalização [59,67,68], vibrações ultrassônicas [8,13], entre outras, vendo sendo testadas. A etapa de dispersão realizada neste trabalho, não envolveu métodos químicos, como já descrito anteriormente, e não se mostrou eficiente.

As imagens de MEV também revelaram que a fratura da matriz polimérica ocorreu por "crazing” ou “craze”. Tal fenômeno ocorre através da propagação de trincas que formam bandeamentos na superfície de fratura. Entretanto, nos nanocompósitos, as cargas atuam com um bloqueio à propagação dessas trincas. A figura 22, mostra esquematicamente como ocorre esse fenômeno.

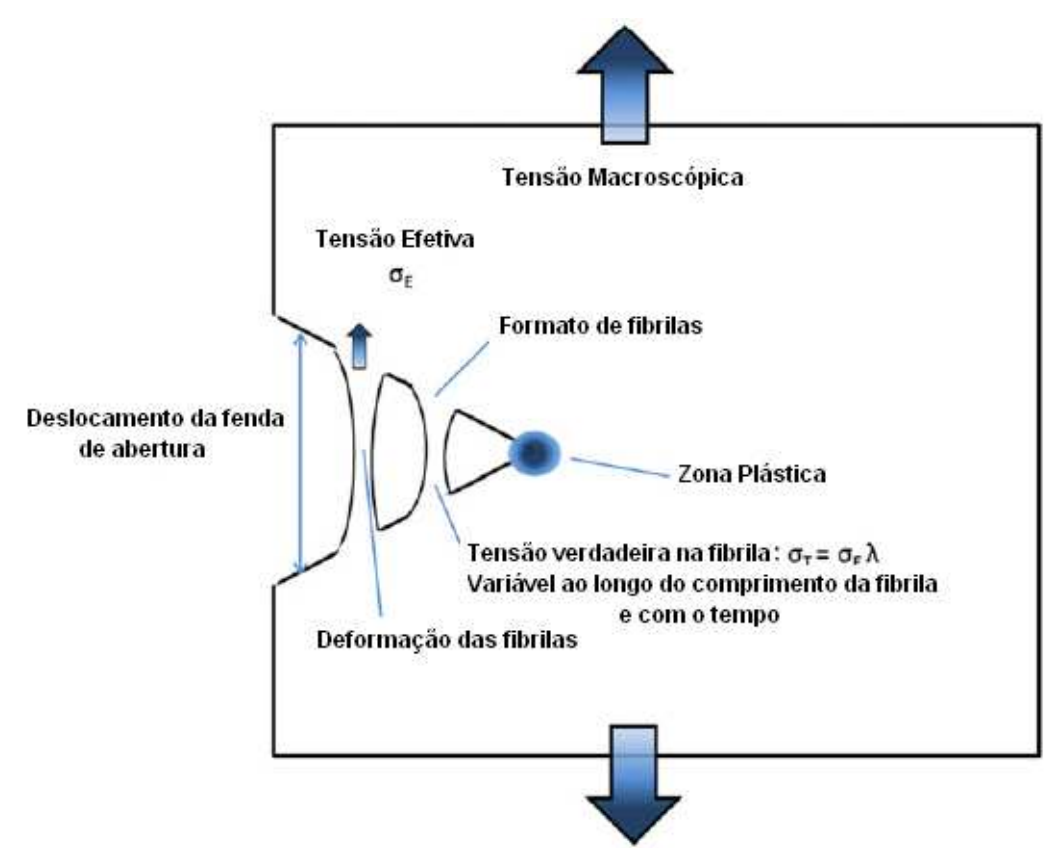

Figura 22 - Representação esquemática do crazing [69]

Uma característica desse tipo de deformação é o desenvolvimento de porosidades, que estão associadas à nucleação e ao crescimento de zonas deformadas plasticamente à frente da trinca. Tais zonas possuem uma estrutura 
fibrilar porosa separadas por vazios [69]. Na figura 23, podemos observar tanto o bandeamento quanto as porosidades características do crazing.
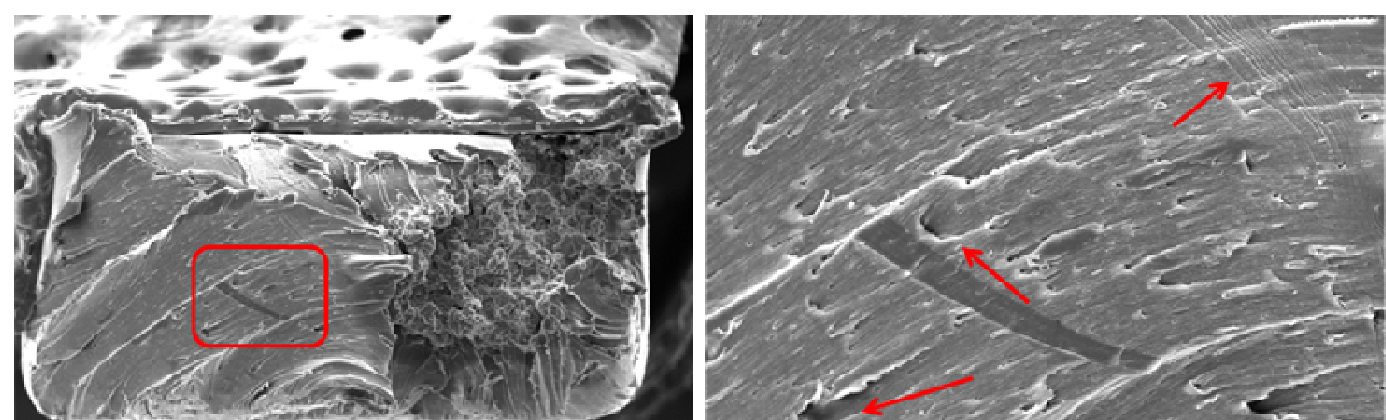

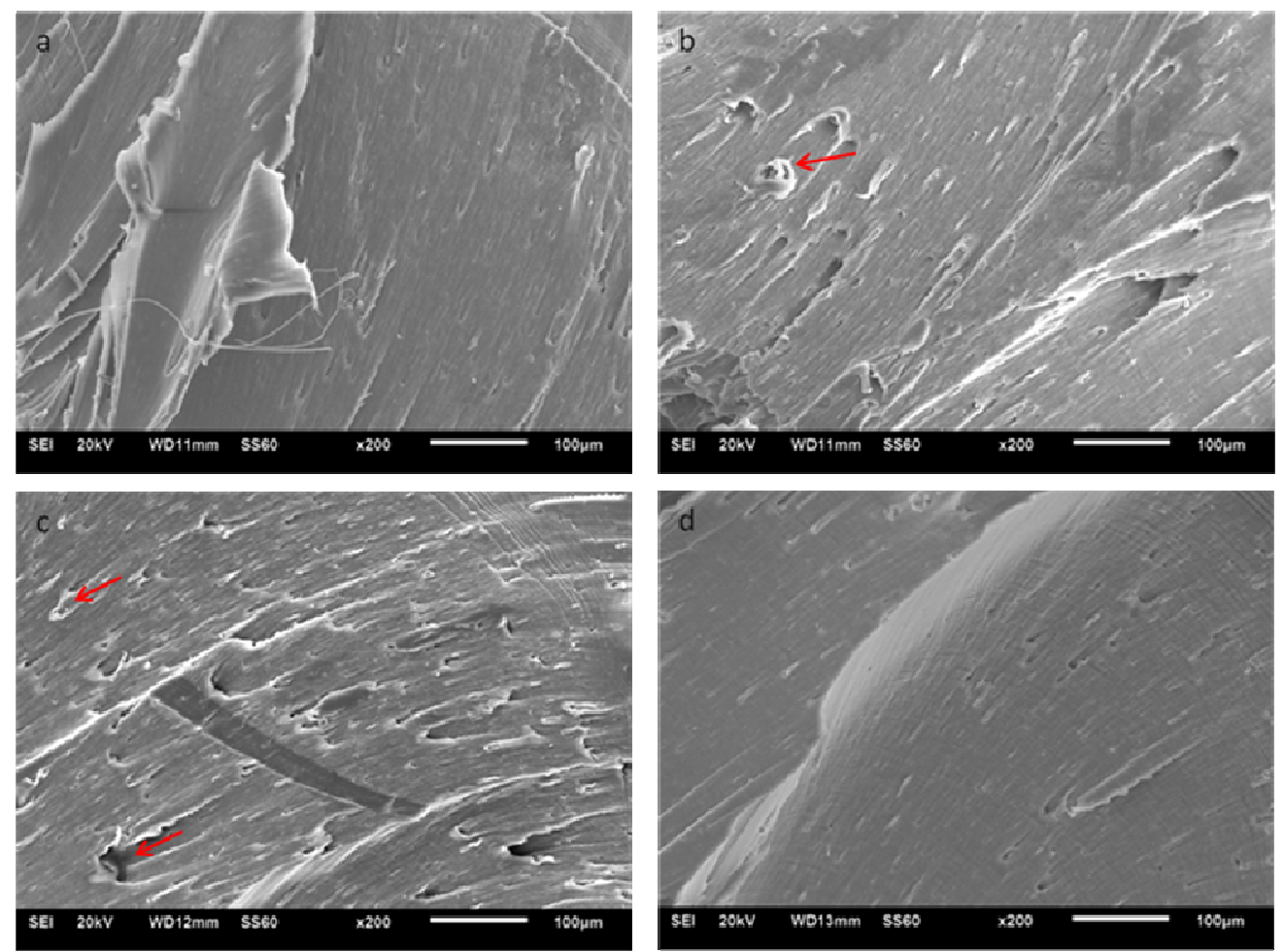

Figura 24 - Imagens de MEV das amostras (a) A1, (b) A2, (c) A3 e (d) A4, evidenciando as aglomerações de cargas nos poros.

\subsection{Ensaio de Tração}

Como já descrito neste trabalho, o valor do módulo de elasticidade da poliamida 11 é da ordem de 1,4 GPa. Entretanto, ao realizar os ensaios de tração, foi encontrado um módulo de elasticidade muito inferior, da ordem de 0,08 GPa. Isso ocorreu porque a poliamida utilizada neste trabalho é reciclada e em sua maioria proveniente de mangueiras. Uma vez que o processo de reciclagem não utiliza plastificantes, entende-se que estes foram adicionados em grande quantidade no processo realizado para a fabricação das mangueiras. Logo, os resultados descritos a seguir, não podem ser diretamente comparados a dados existentes na literatura onde as poliamidas utilizadas não são do tipo recicladas.

A tabela 4 mostra os valores da tensão e deformação na ruptura, módulo de elasticidade e coeficiente de encruamento. Esses valores também estão representados no gráfico 1. Para calcular o módulo de elasticidade, foi definido 
um limite inferior de tensão (5MPa) e um limite superior (10MPa) e a partir dos dados desse intervalo o coeficiente angular da reta foi calculado. Esse coeficiente angular corresponde ao valor do módulo de elasticidade. Os valores apresentados na tabela abaixo são referentes tanto as amostras de poliamida pura (A0 e Ap), quanto aos nanocompósitos fabricados (A1, A2, A3 e A4) e estão separados de acordo com a velocidade do ensaio.

\begin{tabular}{|c|c|c|c|c|}
\hline \multirow{2}{*}{ Amostras } & \multicolumn{4}{|c|}{$10 \mathrm{~mm} / \mathrm{min}$} \\
\hline & $\sigma_{\mathrm{R}}(\mathrm{MPa})$ & $\varepsilon_{R}(\%)$ & $\mathrm{E}(\mathrm{MPa})$ & $\mathbf{n}$ \\
\hline $\mathrm{AO}$ & $45,1 \pm 1,5$ & $500,3 \pm 24,0$ & $75,9 \pm 7,8$ & $0,92 \pm 0,07$ \\
\hline Ap & $46,2 \pm 0,7$ & $495,2 \pm 10,2$ & $81,9 \pm 4,2$ & $0,93 \pm 0,02$ \\
\hline $\mathrm{A} 1$ & $37,0 \pm 4,2$ & $353,5 \pm 60,4$ & $83,1 \pm 5,3$ & $0,88 \pm 0,02$ \\
\hline $\mathrm{A} 2$ & $42,7 \pm 3,4$ & $455,1 \pm 43,9$ & $80,3 \pm 4,5$ & $0,87 \pm 0,01$ \\
\hline A3 & $43,2 \pm 2,3$ & $426,3 \pm 29,0$ & $82,3 \pm 4,8$ & $0,88 \pm 0,01$ \\
\hline A4 & $42,3 \pm 1,7$ & $414,8 \pm 16,6$ & $79,7 \pm 2,8$ & $0,85 \pm 0,02$ \\
\hline
\end{tabular}

\begin{tabular}{|c|c|c|c|c|}
\hline \multirow{2}{*}{ Amostras } & \multicolumn{4}{|c|}{$50 \mathrm{~mm} / \mathrm{min}$} \\
\hline & $\sigma_{\mathrm{R}}(\mathrm{MPa})$ & $\varepsilon_{R}(\%)$ & $\mathrm{E}(\mathrm{MPa})$ & n \\
\hline $\mathrm{AO}$ & $33,6 \pm 5,6$ & $334,7 \pm 107,8$ & $89,5 \pm 5,5$ & $0,88 \pm 0,03$ \\
\hline Ap & $38,9 \pm 2,6$ & $443,6 \pm 37,0$ & $81,0 \pm 7,8$ & $0,88 \pm 0,04$ \\
\hline $\mathrm{A} 1$ & $38,3 \pm 4,3$ & $213,3 \pm 37,7$ & $326,3 \pm 48,6$ & $0,44 \pm 0,03$ \\
\hline $\mathrm{A} 2$ & $41,2 \pm 3,4$ & $463,0 \pm 62,1$ & $88,1 \pm 4,6$ & $0,85 \pm 0,03$ \\
\hline A3 & $39,7 \pm 0,6$ & $220,8 \pm 7,4$ & $363,4 \pm 7,9$ & $0,42 \pm 0,02$ \\
\hline A4 & $37,3 \pm 1,3$ & $378,3 \pm 15,1$ & $86,2 \pm 3,2$ & $0,82 \pm 0,01$ \\
\hline
\end{tabular}

Tabela 4 - Propriedades mecânicas da PA11 e dos nanocompósitos fabricados. 


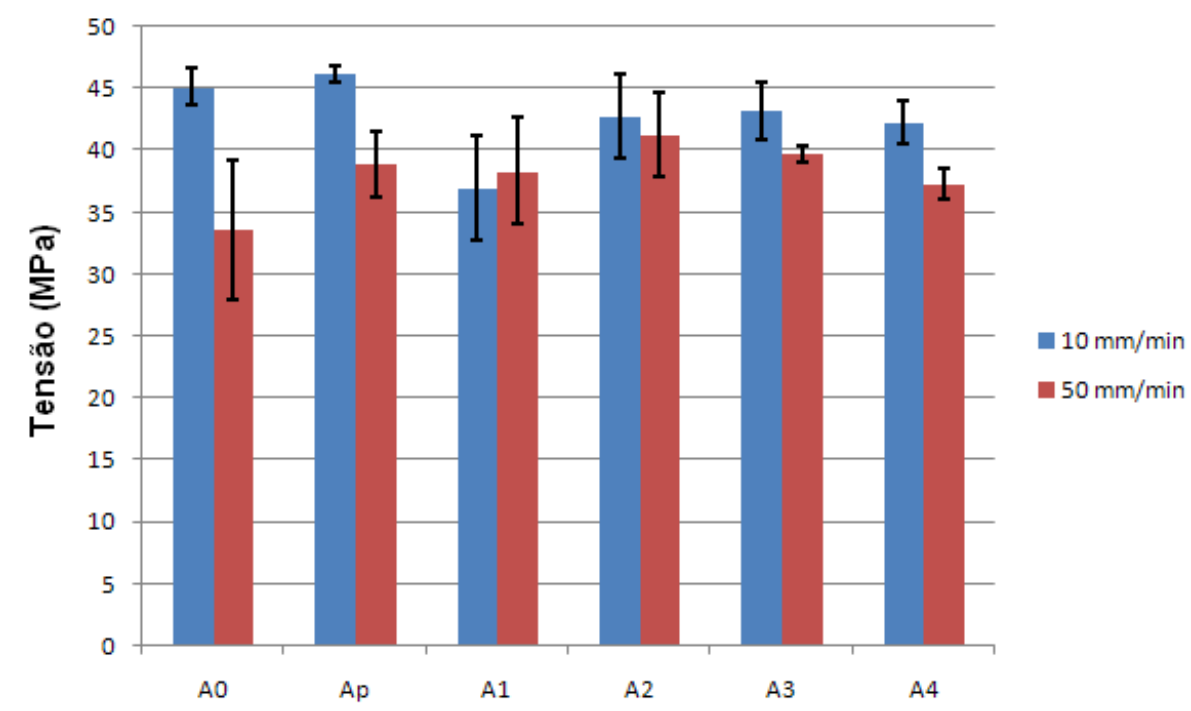

(a)

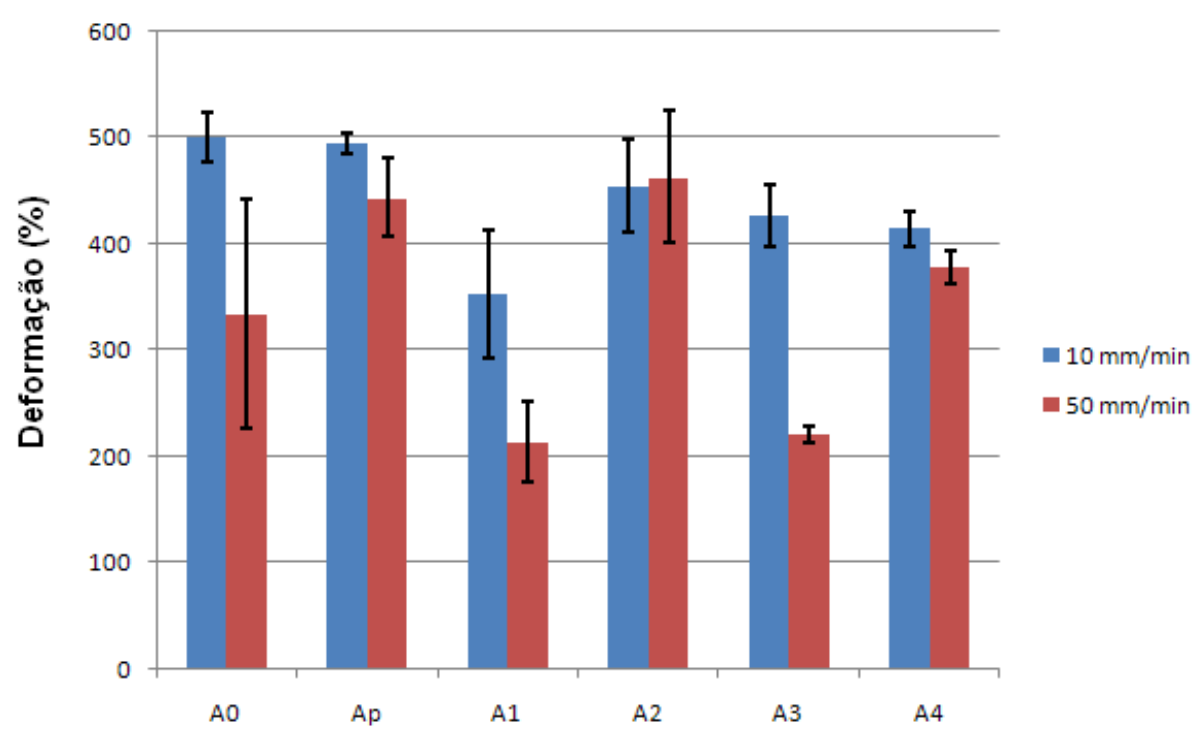

(b) 


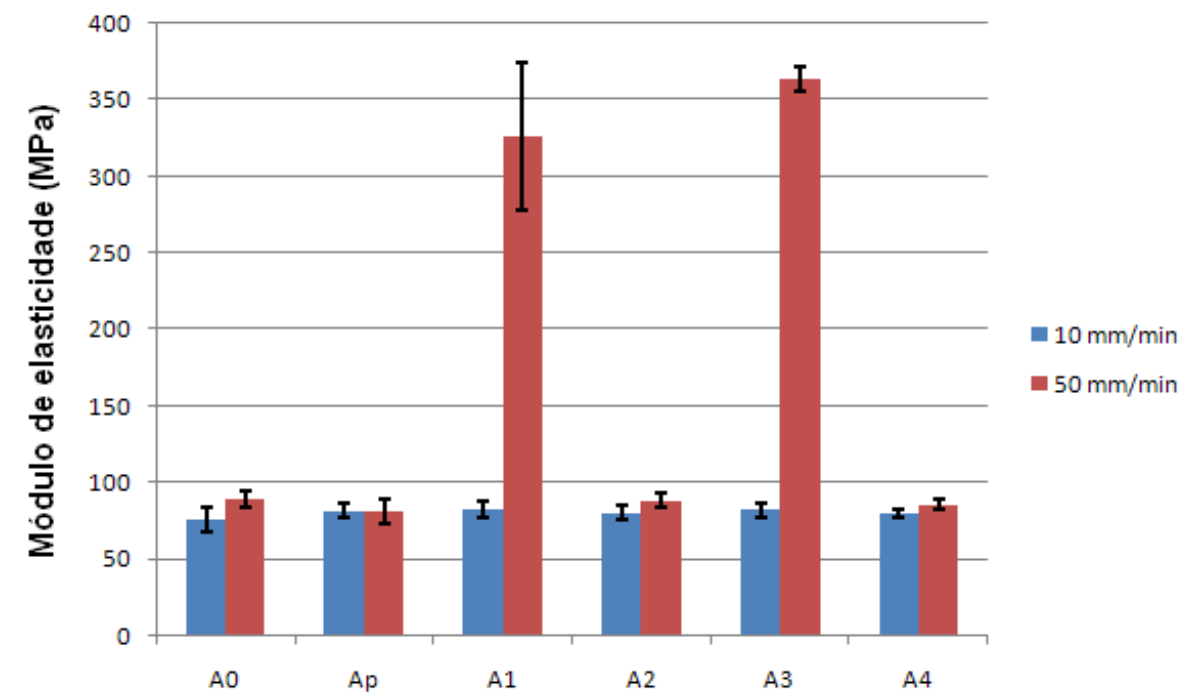

(c)

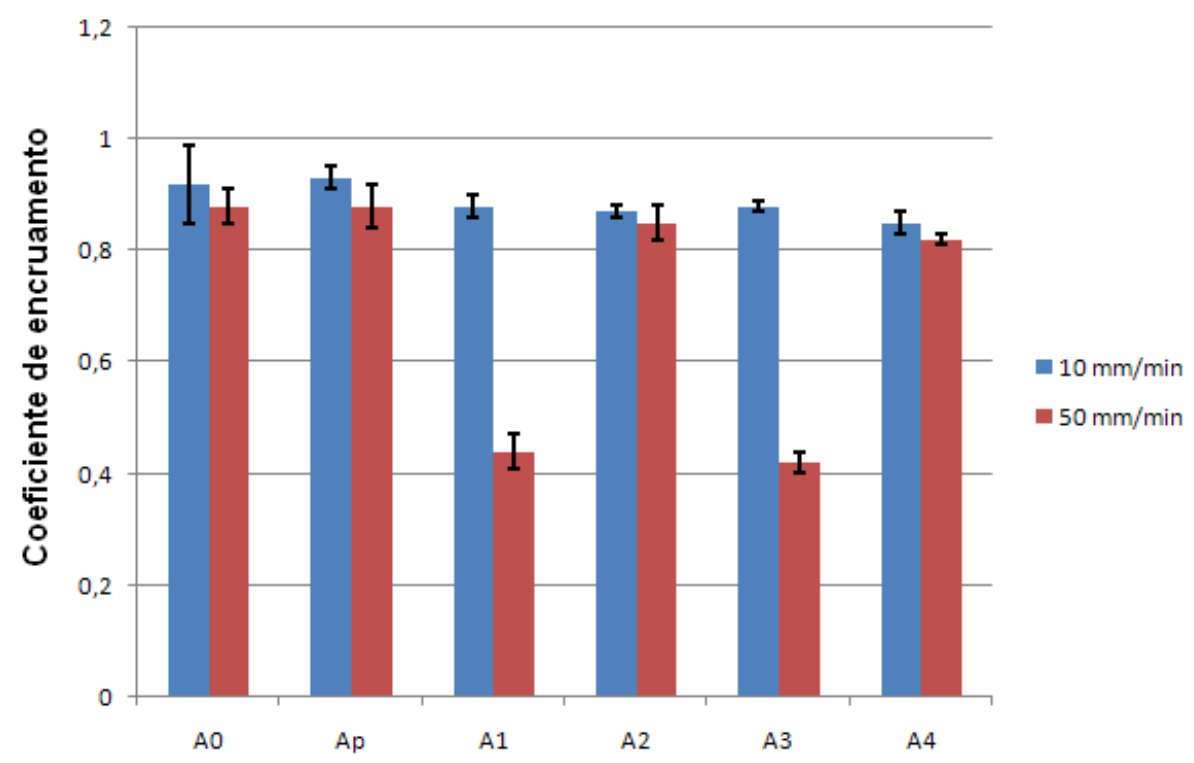

(d)

Gráfico 1 - (a) Tensão, (b) Deformação, (c) Módulo de elasticidade e (d) Coeficiente de encruamento.

Podemos notar que os valores do módulo de elasticidade dos nanocompósitos, obtidos no ensaio de tração com velocidade igual a $10 \mathrm{~mm} / \mathrm{min}$, 
não apresentaram nenhuma melhora significativa quando comparados à poliamida pura. Já para o ensaio com velocidade de $50 \mathrm{~mm} / \mathrm{min}$, conseguimos observar que as amostras A1 e A3 apresentaram uma melhora significativa no módulo de elasticidade quando comparadas à poliamida pura (gráfico 1-(c)), aumentando de $89 \mathrm{MPa}$ (A0) para $326 \mathrm{MPa}$ e $363 \mathrm{MPa}$ respectivamente. Esses valores representam um aumento de $185 \%$ e $200 \%$, que são extremamente altos quando comparados com a literatura, onde são relatados valores em torno de $14 \%$ para nanocompósitos reforçados por nanopartículas [61]. Tal aumento pode estar associado ao fato do módulo inicial ser muito baixo, o que comprovaria a eficiência das cargas na matriz. A figura 25 mostra o comportamento das curvas paras as amostras A0, A1 e A3 no ensaio de tração realizado com a velocidade de $50 \mathrm{~mm} / \mathrm{min}$.

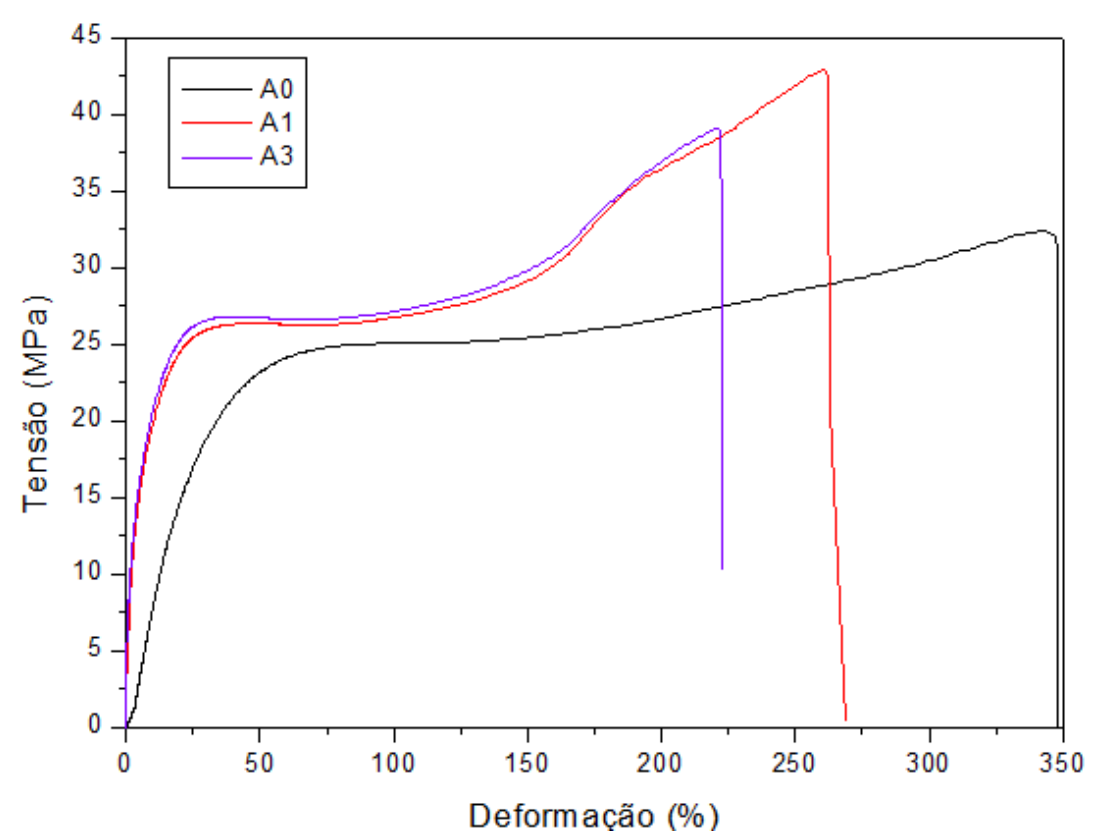

Figura 25 - Curvas tensão x deformação das amostras A0, A1 e A3 a uma velocidade de carregamento de $50 \mathrm{~mm} / \mathrm{min}$.

Esse comportamento demonstra a dependência existente entre os mecanismos de deformação e as propriedades mecânicas, com a velocidade de carregamento (Figura 26). Quanto maior a velocidade de carregamento, maior o 
módulo de elasticidade e a tensão de escoamento e menor a deformação. A redução da porcentagem de deformação está associada a uma diminuição do movimento das cadeias moleculares com o aumento da velocidade [15].
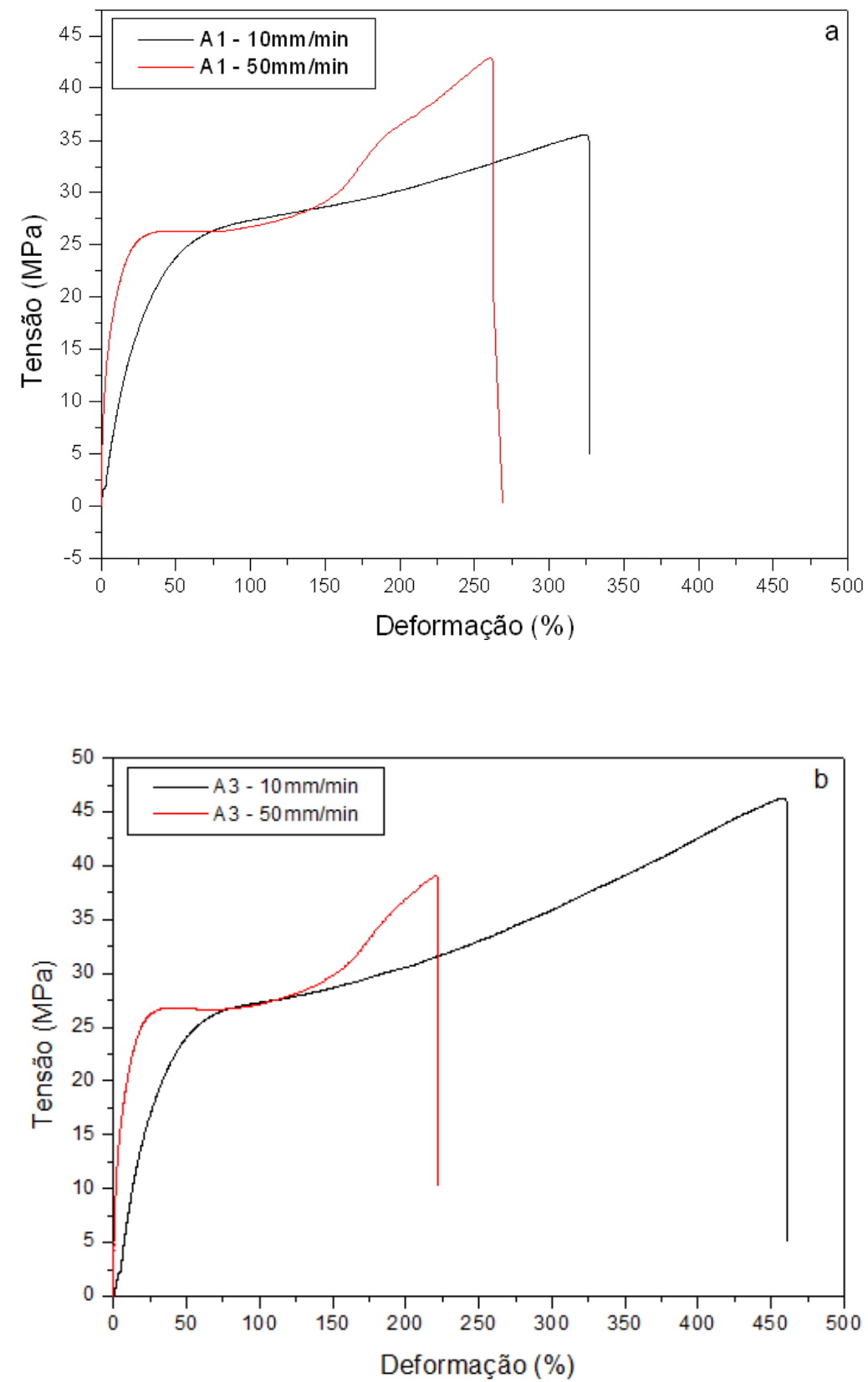

Figura 26 - Curvas tensão x deformação para as diferentes velocidades de carregamento do ensaio de tração para amostra: (a) A1 e (b) A3. 
Outro fator relevante é o coeficiente de encruamento que é uma medida da plasticidade do material. Pela tabela 4, podemos observar que para as amostras A1 e A3 na velocidade de $50 \mathrm{~mm} / \mathrm{min}$, o coeficiente de encruamento reduz à metade quando comparado à poliamida pura. Esse comportamento não era o esperado, uma vez que à medida que o coeficiente de encruamento diminui, o material se torna mais próximo ao idealmente plástico $(n=0)$.

A partir desses valores, avaliou-se que o início do processo de deformação plástica da poliamida pura ocorre com uma maior dificuldade do que a dos nanocompósitos. Já no estágio de deformação plástica macroscópica, as cargas atuaram como inibidores do escoamento das cadeias moleculares dos polímeros, o que fez com que a porcentagem de deformação na fratura fosse bem menor para os nanocompósitos do que para a poliamida pura. Esse comportamento pode ser comprovado pelas micrografias anteriores (figura 24) onde as marcas parabólicas são representativas das cargas que atuaram como inibidoras. Na poliamida pura (A0) não há a presença dessas marcas (figura 27).

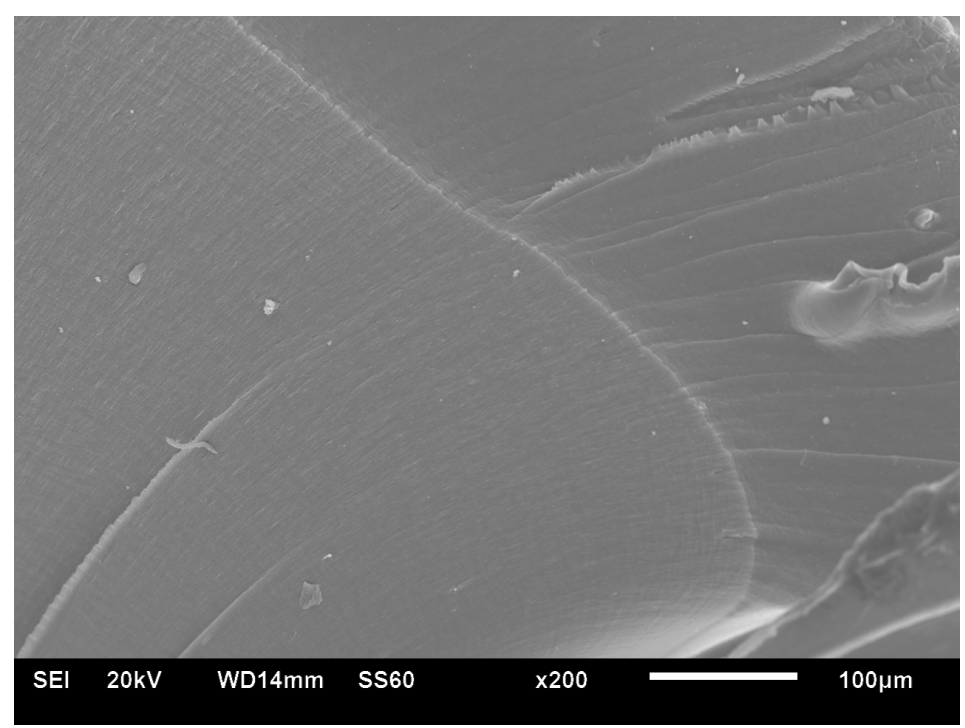

Figura 27 - Micrografia da amostra A0.

A figura 28 exemplifica uma das curvas (A1) que foi linearizada e transformada para a base de logaritmo neperiano para que o coeficiente de encruamento pudesse ser obtido. 


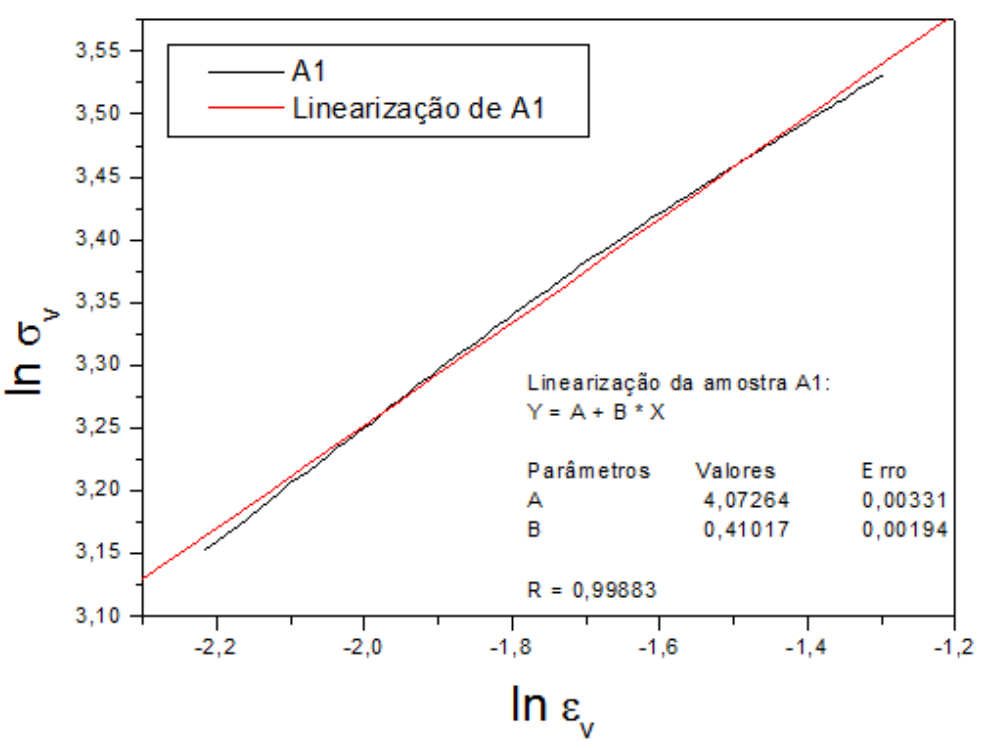

Figura 28 - Linearização da curva da amostra A1.

As amostras A1 e A3, que obtiveram uma melhora nas propriedades mecânicas, também apresentaram aglomerações das cargas. Entretanto, mesmo com aglomerações na ordem de pouca mícrons, as partículas não perderam suas propriedades mecânicas, o que pode ser comprovado pelos resultados obtidos no ensaio de tração dos nanocompósitos. Uma hipótese é que para a amostra A1 apenas uma pequena porcentagem das cargas tenha se aglomerado, o que faria com que as nanopartículas tivessem mantido suas propriedades e cumprido sua função de melhorar as propriedades mecânicas do nanocompósito. Já na amostra A3, como a porcentagem de carga na matriz era bem mais alta (5\%p), acredita-se que as partículas tenham se aglomerado tornando-se micropartículas, mas mantendo suas características mecânicas.

Outra observação importante refere-se ao fato da amostra reforçada com $1 \%$ p de nanotubos (A4) não ter demonstrado nenhuma melhora nas propriedades mecânicas. Como o processamento das amostras alcançou temperaturas em torno de $220^{\circ} \mathrm{C}$, é possível que os nanotubos tenham iniciado o processo de transformação da estrutura de trititanatos para hexatitanatos [55]. Entretanto, essa alteração não seria o suficiente para alterar as propriedades mecânicas dos nanotubos. Sendo assim, acredita-se que esse resultado está diretamente ligado à dispersão da carga na matriz. Como ilustrado nas imagens de MEV (figuras $17 \mathrm{e}$ 21), as cargas formaram aglomerações com tamanhos na ordem de mícrons, 
perdendo assim suas características mecânicas medidas quando na ordem de nanômetros. Diferentemente das nanopartículas, os nanotubos não mantém as mesmas características quando estão aglomerados.

Para a poliamida processada (Ap) e a poliamida pura (A0), podemos observar que houve um pequeno aumento na \% de deformação e também na tensão de ruptura da Ap. Essa variação está associada ao processo de câmara de mistura e a moagem ao qual esta amostra foi submetida, diferentemente da A0, revelando que todas as etapas do processamento influenciam na fabricação do nanocompósito.

\subsection{Termogravimetria (TGA)}

As análises termogravimétricas foram realizadas com o intuito de avaliar a resposta térmica do polímero e dos nanocompósitos. A figura 29 (a) e (b) apresenta as curvas de decomposição térmica e suas derivadas, respectivamente, tanto da poliamida pura quanto dos nanocompósitos.

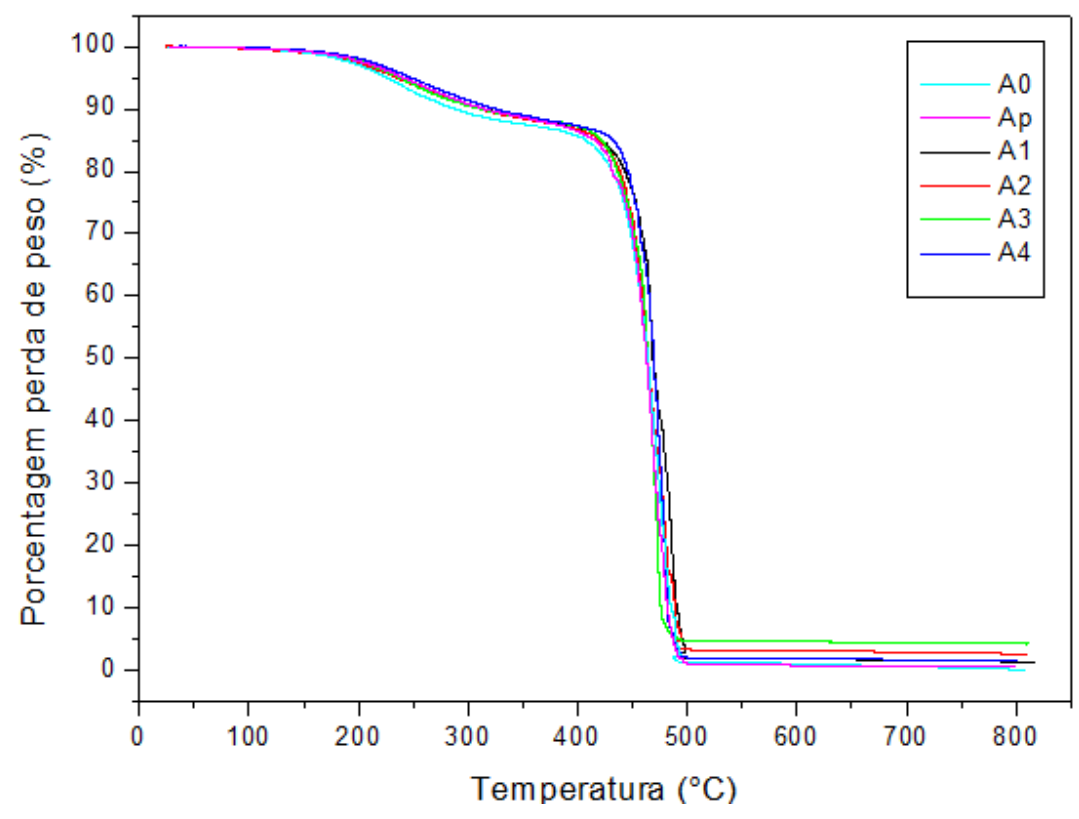

(a) 


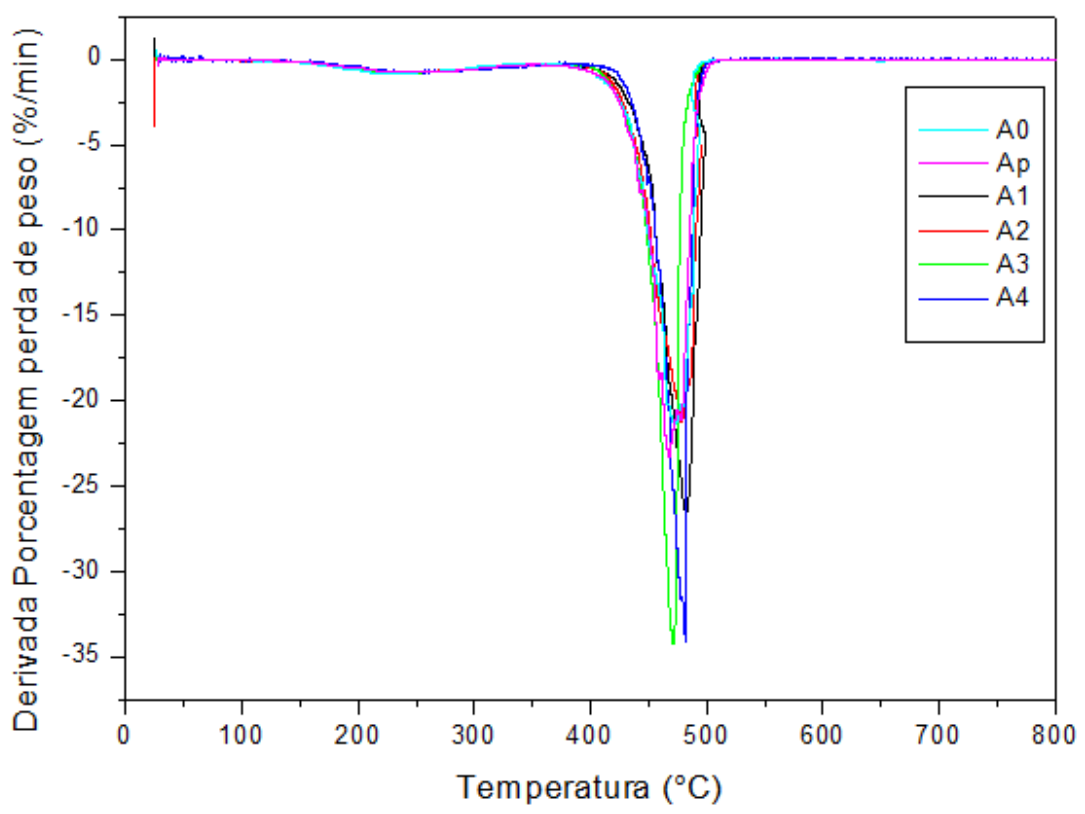

(b)

Figura 29 - (a) Curvas da TGA e (b) curvas da $1^{\text {a }}$ derivada da TGA.

Os polímeros formados por um único tipo de monômero (homopolímeros) têm como característica uma curva com um único estágio de decomposição. Entretanto, neste caso, podemos observar dois diferentes estágios de perda de massa. O primeiro estágio é referente à perda de plastificantes que foram utilizados no processo de fabricação da poliamida [70] e corresponde a uma perda de massa em torno de $12 \%$ a temperaturas entre $170^{\circ} \mathrm{C}$ até $360^{\circ} \mathrm{C}$. Como já descrito anteriormente, a poliamida utilizada é um material reciclado, em sua maioria, de mangueiras e por isso foram adicionados plastificantes em seu processo de fabricação.

Pela figura 30, podemos observar que a poliamida pura (A0) obteve uma perda de massa maior do que a poliamida processada e os nanocompósitos. Esse resultado está associado ao fato da amostra A0 ter sido a única que não passou pela etapa da câmara de mistura, que foi realizada a temperaturas em torno de $220^{\circ} \mathrm{C}$. Ao passar pela câmara de mistura, as amostras já tiveram uma perda de massa referente aos plastificantes, e por isso apresentaram uma perda menor durante a análise termogravimétrica. 


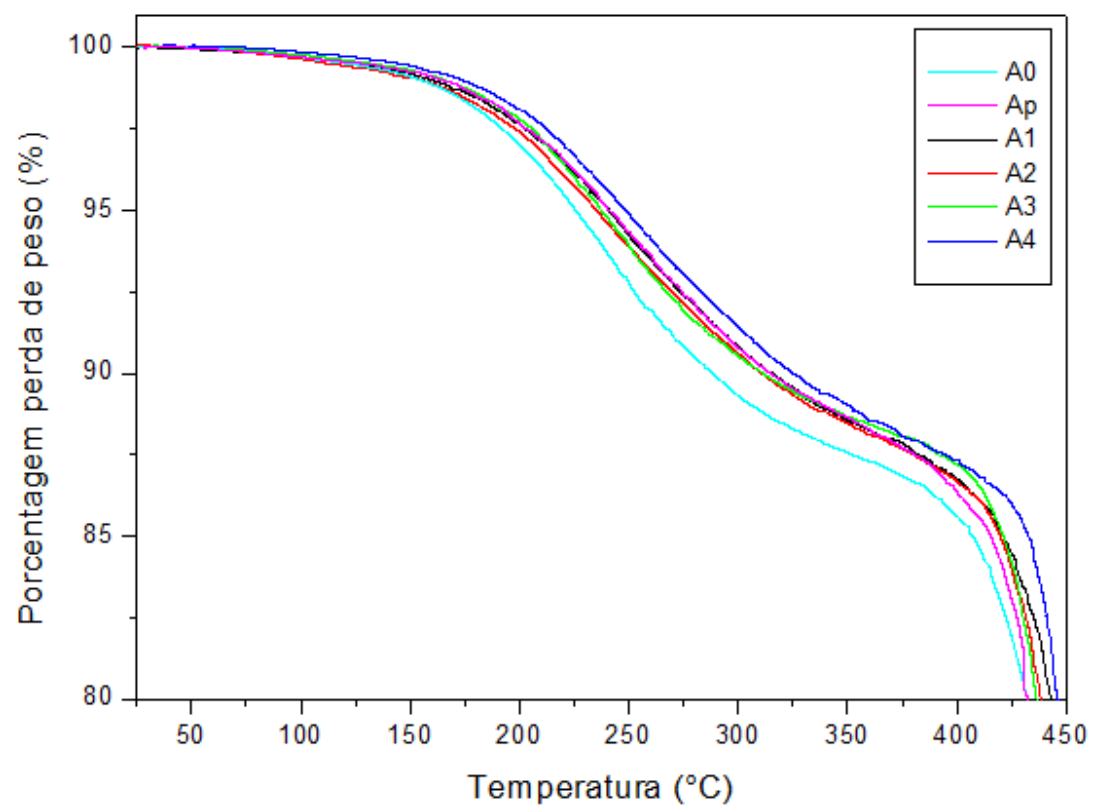

Figura 30 - Primeiro estágio de perda de massa da poliamida 11(A0 e Ap) e dos nanocompósitos (A1, A2, A3 e A4)

O segundo estágio de degradação é referente à degradação do próprio material e ocorre a temperaturas iniciando em torno de $440^{\circ} \mathrm{C}$. Nesta etapa ocorre a maior taxa de degradação da amostra. A temperatura de degradação encontrada para a poliamida 11 neste trabalho ficou um pouco acima da representada por Liu et al [10] e já demonstrada anteriormente (figura 6).

Para a amostra A4, vale ressaltar também a perda de massa sofrida pelos nanotubos de titanato, que possuem dois processos de perda de massa distintos [71]. O primeiro processo consiste numa perda de massa referente à água adsorvida na superfície devido à umidade do ar e ocorre a temperaturas de até $100^{\circ} \mathrm{C}$. Esse valor pode variar de acordo com o tempo de armazenamento desses materiais e também com a pressão atmosférica. O segundo processo se refere à perda de água contida na composição estrutural dos nanotubos $\left(\mathrm{Na}_{\mathrm{x}} \mathrm{H}_{\mathrm{x}-2} \mathrm{Ti}_{3} \mathrm{O}_{7 .} n \mathrm{H}_{2} \mathrm{O}\right)$ e ocorre a temperaturas entre $100^{\circ} \mathrm{C}$ e $500^{\circ} \mathrm{C}$.

A figura 31 mostra as curvas obtidas pela TGA para o TTNT e para o P-25 realizada por Abreu [57]. 


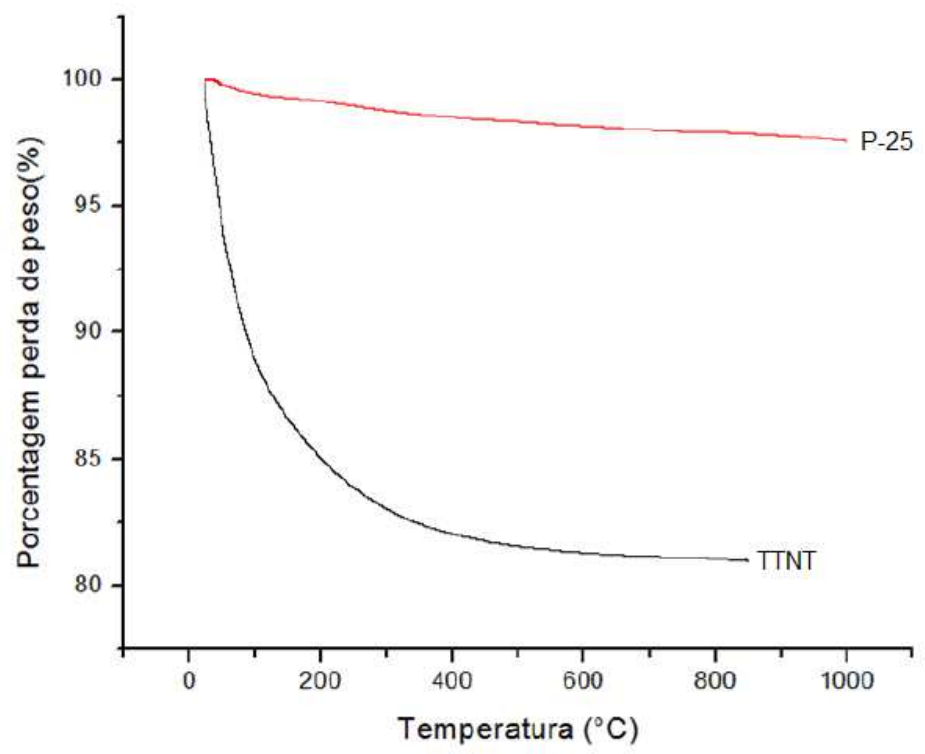

Figura 31 - Curvas de TGA dos nanotubos de titanato (TTNT) e das nanopartículas comerciais (P-25) [57].

\begin{tabular}{|c|c|c|c|c|}
\hline Amostras & $\begin{array}{c}\text { \% massa } \\
\text { perdida } \\
\text { (1o estágio) } \\
\end{array}$ & $\begin{array}{c}\% \text { massa } \\
\text { perdida } \\
\text { (2o estágio) } \\
\end{array}$ & $\begin{array}{c}\text { Temperatura } \\
\text { de degradação } \\
\left({ }^{\circ} \mathrm{C}\right)\end{array}$ & Massa final (\%) \\
\hline AO & 12,0 & 87,9 & 442,9 & $0,7 \%$ \\
\hline Ap & 11,6 & 87,9 & 446,7 & $0,5 \%$ \\
\hline A1 & 11,6 & 87,1 & 457,6 & $1,3 \%$ \\
\hline $\mathrm{A} 2$ & 11,0 & 86,5 & 443,8 & $2,5 \%$ \\
\hline A3 & 10,8 & 85,0 & 452,2 & $4,2 \%$ \\
\hline A4 & 11,5 & 87,1 & 456,0 & $1,5 \%$ \\
\hline
\end{tabular}

Tabela 5 - \% massa perdida e temperatura de degradação das amostras 
Podemos notar que houve um aumento na temperatura de degradação das amostras A1, A3 e A4, sendo a amostra A1 a que apresentou maior temperatura. Os aumentos foram respectivamente em torno de $15^{\circ} \mathrm{C}, 9^{\circ} \mathrm{C}$ e $13^{\circ} \mathrm{C}$. Outra observação é em relação à \% massa final. Esta deveria ser igual a \% de carga adicionada na matriz, entretanto tivemos um erro absoluto na faixa de $-0,8 \%$ (A3) a $+0,5 \%$ (A4). Como somente uma amostra foi analisada, esse erro pode estar refletindo variações locais. Para as amostras de poliamida pura (A0 e Ap), esta \% de massa final pode estar relacionada a impurezas.

Podemos concluir com esses resultados, que para as amostras A1 e A3, as cargas não só melhoraram as propriedades mecânicas dos nanocompósitos como também as propriedades térmicas. Mesmo com a aglomeração das cargas observada no MEV, a fabricação dessas duas amostras foi bem sucedida em relação às suas características mecânicas e térmicas. 


\section{6.}

\section{Conclusões}

No presente trabalho foram fabricados nanocompósitos de matriz polimérica (poliamida 11) e cargas à base de $\mathrm{TiO}_{2}$ (nanotubos de titanato e nanopartículas de $\mathrm{TiO}_{2}$ ). $\mathrm{O}$ objetivo era analisar o comportamento térmico e mecânico dos nanocompósitos e compará-los com a poliamida pura.

A ideia inicial da utilização da poliamida 11 como matriz era o desenvolvimento de um material com propriedades superiores para a sua aplicação em risers. Entretanto, ao longo do desenvolvimento do projeto, quando o ensaio mecânico foi realizado, foi um encontrado um módulo de elasticidade inferior ao reportado na literatura. Ao entrar em contato com o fornecedor, foi descoberto que a poliamida 11 comprada era um material reciclado e proveniente, em sua maioria, de mangueiras. Como não sabemos como ocorre o processo de fabricação dos materiais que foram reciclados, concluímos que a poliamida obtida possui um teor muito alto de plastificantes, o que explica o baixo valor do módulo de elasticidade. Sendo assim, este material não pode ser comparado aos valores encontrados na literatura, e também, não podemos mais estudá-lo com o foco em aplicações offshore, que requerem um maior valor do módulo para a sua aplicação.

Das análises de $\mathrm{MEV}$, podemos concluir que o método de dispersão utilizado não foi eficiente, uma vez que foram encontradas aglomerações da ordem de 3-4 $\mu \mathrm{m}$. Sendo assim, faz-se necessário o estudo de outras técnicas de dispersão como vibrações ultrassônicas ou até mesmo métodos químicos, como a funcionalização.

Entretanto, mesmo as cargas tendo aglomerado, pode-se observar uma melhora no módulo de elasticidade das amostras A1 (poliamida $11 \mathrm{com} \mathrm{1 \% p} \mathrm{de}$ nanopartículas de $\mathrm{TiO}_{2}$ ) e A3 (poliamida 11 com 5\%p de nanopartículas de $\mathrm{TiO}_{2}$ ) com um aumento de $89 \mathrm{MPa}$ (A0 - poliamida 11 pura) para $326 \mathrm{MPa}$ e $363 \mathrm{MPa}$ respectivamente. Esperava-se que a amostra A4, que foi reforçada por $1 \% \mathrm{p}$ de nanotubos de titanato, apresentasse alguma melhora, mas aparentemente, o efeito 
da aglomeração nos nanotubos influencia mais na perda de suas propriedades mecânicas do que nas nanopartículas.

O resultado das análises térmicas (TGA) revelou um aumento na temperatura de degradação das amostras $\mathrm{A} 1, \mathrm{~A} 3$ e $\mathrm{A} 4$ em torno de $15^{\circ} \mathrm{C}, 9^{\circ} \mathrm{C}$ e $13^{\circ} \mathrm{C}$ respectivamente. Mesmo a amostra A4 não tendo revelado nenhuma melhora nas propriedades mecânicas, pode-se comprovar a eficiência dos nanotubos quanto às propriedades térmicas.

Por fim, podemos concluir que o processo utilizado para a fabricação dos nanocompósitos foi eficiente e resultou em algumas melhoras do material. 


\section{Sugestões}

A seguir, foram listadas algumas sugestões para que o método possa ser aperfeiçoado em trabalhos futuros:

- Fabricar nanocompósitos reforçados por nanotubos de titanato com diferentes concentrações de cargas e acima de $1 \%$ p.

- Melhorar a técnica de dispersão das cargas na matriz polimérica utilizando vibrações ultrassônicas, funcionalização ou algum outro método citado na literatura, pois essa etapa é crucial para obter bons resultados.

- Quantificar os aglomerados fazendo um mapeamento das regiões.

- Avaliar a cristalinidade dos nanocompósitos fabricados.

- Avaliar o comportamento reológico das misturas. 


\section{8.}

\section{Bibliografia}

1 WANG, B.; HU, G.; ZHAO, X.; GAO, F.; Preparation and characterization of nylon 611 copolymer, Materials Letters, 60 (2002) 2715-2717.

2 NOVAES, J.P.Z.; Avaliação do comportamento dinâmico e evolução estrutural das poliamidas 6 e 11 em diferentes estágios de envelhecimento, 2005, Dissertação de Mestrado, Universidade Federal do Rio de Janeiro, Rio de Janeiro: 2010.

3 GOJNY, F.H.; WICHMANN, M.H.G.; FIEDLER, B.; KINLOCH, I.A.; BAUHOFER, W.; WINDLE, A.H.; SCHULTE, K.; Evaluation and identification of electrical and thermal conduction mechanisms in carbon nanotube/epoxy composites, Polymer, 47 (2006) 2036-2045.

4 SANTOS, K.S.; LIBERMAN, S.A.; OVIEDO, M.A.S.; MAULER, R.S.; Optimization of the mechanical properties of polypropylene-based nanocomposite via the addition of a combination of organoclays, Composites: Part A, 40 (2009) 1199-1209.

5 MOORE, A.L.; CUMMINGS, A.T.; JENSEN, J.M.; SHI, L.; KOO, J.H.; Thermal Conductivity Measurements of Nylon 11-Carbon Nanofiber Nanocomposites, Journal of Heat Transfer-Transactions of the ASME, 131 (2009).

6 HA, H.; KIM, S.C.; HA, K.; Morphology and Properties of Polyamide/Multiwalled Carbon Nanotube Composites, Macromolecular Research, 18 (2010) 660-667.

7 LAO, S.C.; WU, C.; MOON, T.J.; KOO, J.H.; MORGAN, A.; PILATO, L.; WISSLER, G.; Flame-retardant Polyamide 11 and 12 Nanocomposites: Thermal and Flammability Properties; Journal of Composite Materials 43 (2009) 18031818.

8 UMEK, P.; HUSKIC, M.; SKAPIN, A.S.; FLORJANCIC, U.; ZUPANCIC, B.; EMRI, I.; ARCON, D.; Structural and Mechanical Properties of Polystyrene 
Nanocomposites With 1D Titanate Nanostructures Prepared by an Extrusion Process, Polymer Composites, 30 (2009) 1318-1325.

9 SAHA, M.C.; KABIR, M.E.; JEELANI, S.; Enhancement in thermal and mechanical properties of polyurethane foam infused with nanoparticles; Materials Science and Engineering A, 479 (2008) 213-222.

10 LIU, T.; LIM, K.P.; TJIU, W.C.; PRAMODA, K.P.; CHEN, Z.-K.; Preparation and characterization of nylon 11/organoclay nanocomposites, Polymer, 44 (2003) 3529-3535.

11 AJAYAN, P.M.; STEPHAN, O.; REDLICH, PH.; COLLIEX, C.; Carbon nanotubes as removable templates for metal oxide nanocomposites and nanostructures, Nature, 375 (1995) 564-567.

12 MAGO, G.; KALYON, D.M.; FISHER, F.T.; Nanocomposites of Polyamide11 and Carbon Nanostructures: Development of Microstructure and Ultimate Properties Following Solution Processing, Journal of Polymer Science Part BPolymer Physics, 49 (2011) 1311-1321.

13 CHATTERJEE, A.; ISLAM, M.S.; Fabrication and characterization of $\mathrm{TiO}_{2-}$ epoxy nanocomposite; Materials Science and Engineering A, 487 (2008) 574585 .

14 LEE, H.S.; IM, S.J.; KIM, J.H.; KIM, H.J.; KIM, J.P.; MIN, B.R.; Polyamide thin-film nanofiltration membranes containing $\mathrm{TiO}_{2}$ nanoparticles, Desalination, 219 (2008) 48-56.

15 STARKOVA, O.; ZHANG, Z.; ZHANG, H.; PARK, H.-W.; Limits of the linear viscoelastic behavior of polyamide 6,6 filled with $\mathrm{TiO}_{2}$ nanoparticles: Effect of strain rate, temperature and moisture, Materials Science and Engineering A, 498 (2008) 242-247.

16 HOYER, P.; Formation of a titanium dioxide nanotube array, Langmuir, 12 (1996) 1411-1413.

17 KASUGA, T.; HIRAMATSU, M.; HOSON, A.; SEKINO, T.; NIIHARA, K.; Formation of titanium oxide nanotube, Langmuir, 14 (1998) 3160-3163.

18 KASUGA, T.; HIRAMATSU, M.; HOSON, A.; SEKINO, T.; NIIHARA, K.; Titania nanotubes prepared by chemical processing, Advanced Materials, 11 (1999) 1307-1311. 
19 GONG, D.; GRIMES, C.A.; VARGHESE, O.K.; HU, W.C.; SINGH; R.S.; CHEN; Z. DICKEY, E.C.; Titanium oxide nanotube arrays prepared by anodic oxidation, Journal of Materials Research, 16 (2001) 3331-3334.

20 IMAI, H.; TAKEI, Y.; SHIMIZU, K.; MATSUDA, M.; HIRASHIMA, H.; Direct preparation of anatase $\mathrm{TiO}_{2}$ nanotubes in porous alumina membranes, Journal of Materials Chemistry, 9 (1999) 2971-2972.

21 HUSSAIN, F.; HOJJATI, M.; OKAMOTO, M.; GORGA, R.E.; Review article: Polymer-matrix Nanocomposites, Processing, Manufacturing, and Application: An Overview, Journal of Composite Materials, 40 (2006) 1511.

22 ASHBY, M.F.; FERREIRA, P.J.; Nanomaterials, Nanotechnologies and Design - An Introduction for Engineers and Architects, USA, 2009.

23 IIJIMA, S.; Helical Microtubules of Graphitic Carbon, Nature, 354 (1991) 5658.

24 SPAHR, M.E.; BITTERLI, P.; NESPER, R.; MULER, M.; KRUMEICH, F.; NISSEN, H.U.; Redox-Active Nanotubes of Vanadium Oxide, Angewandte Chemie International, 37 (1998) 1263-1265.

25 SATISHKUMAR, B.C.; GOVINDARAJ, A.; VOGL, E.M.; BASUMALLICK, L.; RAO, C.N.R.; Oxide nanotubes prepared using carbon nanotubes as templates, Journal of Materials Research, 12 (1997) 604-606.

26 NAKAMURA, H.; MATSUI, Y.; Silica-gel nanotubes obtained by the sol-gel method, Journal of the American Chemical Society, 117 (1995) 2651-2652.

27 CHUNG, H.; DAS, S.; Functionally graded Nylon-11/sílica nanocomposites produced by selective laser sintering, Material Science and Engineering A, 487 (2008) 251-257.

28 OU, Y.C.; YANG, F.; YU, Z.Z.; New Conception on the Toughness of Nylon 6/Silica Nanocomposites Prepared via In Situ Polymerization, Journal of Polymer Science Part B-Polymer Physics, 36 (1998) 789-795.

29 MA, D.; HUGENER, T.A.; SIEGEL, R.W.; CHRISTERSON, A.; MARTENSSON, E.; ONNEBY, C.; SCHADLER, L.; Influence of Nanoparticle Surface Modification on the Electrical Behaviour of Polyethylene Nanocomposites, Nanotechnology, 16 (2005) 724-731.

30 HU, Y.; SHEN, L.; YANG, H.; WANG, M.; LIU, T.; LIANG, T.; ZHANG, J.; Nanoindentation studies on Nylon 11/clay nanocomposites, Polymer Testing, 25 (2006) 492-497. 
31 ZHANG, Z.; YANG, J.L.; FRIEDRICH, K.; Creep resistant polymeric nanocomposites, Polymer, 45 (2004) 3481-3485.

32 BISPO, C. E.; Efeito do envelhecimento da poliamida 11 em petróleo sobre as propriedades térmicas e mecânicas; 2008, Dissertação de Mestrado, Universidade Federal do Rio de Janeiro, Rio de Janeiro: 2010.

33 TIPOS DE POLÍMEROS; Disponível em: http://polimeros.no.sapo.pt /tipos.htm; Acesso em 04/02/2012.

34 DHANALAKSHMI, M.; JOG, J.P.; Preparation and characterization of electrospun fibers of Nylon 11; Express Polymer Letters, 2 (2008) 540-545.

35 FERNANDEZ, J.O.; SWALLOWE, G.M.; LEE, S.F.; Crystallization of Nylon 11 Under Compressive High Strain Rates; Journal of Applied Polymer Science, 80 (2001) 2031-2038.

36 FELIX-HENRY, A.; Flexible pipe level 1: Applications and design, Technip, Aberdeen (Escócia), Janeiro 2007.

37 COSTA, A.C.F.M.; VILAR, M.A.; LIRA, H.L.; KIMINAMI, R.H.G.A.; GAMA, L.; Síntese e Caracterização de Nanopartículas de $\mathrm{TiO}_{2}$, Cerâmica, 52 (2006) 324.

38 BURDA, C.; CHEN, X.; NARAYANAN, R.; EL-SAYED, M.A.; Chemistry and Properties of Nanocrystals of Different Shapes, Chemical Reviews, 105 (2005) 1025-1102.

39 WANG, W.Z.; VARGHESE, O.K.; PAULOSE, M.; GRIMES, C.A.; WANG, Q.L.; DICKEY, E.C.; A study on the growth and structure of titania nanotubes, Journal of Materials Research, 19 (2004) 417.

40 YAO, B.D.; CHAN, Y.F.; ZHANG, X.Y.; ZHANG, W.F.; YANG, Z.Y.; WANG, N.; Formation mechanism of $\mathrm{TiO}_{2}$ nanotubes, Applied Physics Letters, 82 (2003) 281-283.

41 WANG, Y.Q.; HU, G.Q.; DUAN, X.F.; SUN, H.L.; XUE, Q.K.; Microstructure and formation mechanism of titanium dioxide nanotubes, Chemical Physics Letters, 365 (2002) 427-431.

42 ZHANG Q.; GAO, L.; SUN, L.; ZHENG, S.; Preparation of long $\mathrm{TiO}_{2}$ nanotubes from ultrafine rutile nanocrystals, Chemistry Letters, (2002) 226-227. 43 DU, G.H.; CHEN, Q.; CHE, R.C.; YUAN, Z.Y.; PENG, L.M.; Preparation and structure analysis of titanium oxide nanotubes, Applied Physics Letters, 79 (2001) 3702-3704. 
44 CHEN, Q.; ZHOU, W.; DU, G.; PENG; L.M.; Trititanate nanotubes made via a single alkali treatment, Advanced Materials, 14 (2002) 1208.

45 YUAN, Z.Y.; SU, B.L.; Titanium oxide nanotubes, nanofibers and nanowires, Colloids and Surfaces A, 241 (2004) 173.

46 THORNE, A.; KRUTH, A.; TUNSTALL, D.; IRVINE, J.T.S.; ZHOU, W.J.; Formation, structure, and stability of titanate nanotubes and their proton conductivity, Journal of Physical Chemistry B, 109 (2005) 5439-5444.

47 CHEN, Q.; DU, G.; ZHANG; S.; PENG, L.M.; The structure of trititanate nanotubes, Acta Crystallographica Section B-Structural Science, 58 (2002) 587-593.

48 SUZUKI, Y.; YOSHIKAWA, S.; Synthesis and thermal analyses of $\mathrm{TiO}_{2^{-}}$ derived nanotubes prepared by the hydrothermal method, Journal of Materials Research, 19 (2004) 982-985.

49 SUN, X.M.; LI, Y.D.; Synthesis and characterization of ion-exchangeable titanate nanotubes, Chemistry-A European Journal, 9 (2003) 2229-2238.

50 BAVYKIN, D.V.; PARMON, V.N.; LAPKIN, A.A.; WALSH, F.C.; The effect of hydrothermal conditions on the mesoporous structure of $\mathrm{TiO}_{2}$ nanotubes, Journal of Materials Chemistry, 14 (2004) 3370-3377.

51 YOSHIDA, R.; SUZUKI, Y.; YOSHIKAWA, S.; Effects of synthetic conditions and heat-treatment on the structure of partially ion-exchanged titanate nanotubes, Materials Chemistry and Physics, 91 (2005) 409-416.

52 NAKAHIRA, A.; KATO, W.; TAMAI, M.; ISSHIKI, T.; NISHIO, K.; Synthesis of nanotube from a layered $\mathrm{H}_{2} \mathrm{Ti}_{4} \mathrm{O}_{9}$ center dot $\mathrm{H}_{2} \mathrm{O}$ in a hydrothermal treatment using various titania sources, Journal of Materials Science, 39 (2004) 4239-4245.

53 MA, R.; BANDO, Y.; SASAKI, T.; Nanotubes of lepidocrocite titanates, Chemical Physics Letters, 380 (2003) 577-582.

54 MA, R.; FUKUDA, K.; SASAKI, T.; OSADA, M.; BANDO, Y.; Structural features of titanate nanotubes/nanobelts revealed by Raman, X-ray absorption fine structure and electron diffraction characterizations, Journal of Physical Chemistry B, 109 (2005) 6210-6214.

55 MORGADO, E.; JARDIM, P.M.; MARINKOVIC, B.; RIZZO, F.C.; ABREU, M.A.S.; ZOTIN, J.L.; ARAÚJO, A.S.; Multistep structural transition of hydrogen 
trititanate nanotubes into $\mathrm{TiO}_{2}-\mathrm{B}$ nanotubes: a comparison study between nanostructured and bulk materials, Nanotechnology, 18 (2007).

56 MORGADO, E.; ABREU, M.A.S.; PRAVIA, O.R.C.; MARINKOVIC, B.A; JARDIM, P.M.; RIZZO, F.C.; ARAUJO, A.S.; A study on the structure and thermal stability of titanate nanotubes as a function of sodium content, Solid State Sciences, 8 (2006) 888-900.

57 ABREU, M.A.S.; Síntese e caracterização de nanomateriais a base de $\mathbf{T i O}_{2}$ e seu uso no abatimento fotocatalítico de Nox.; 2010, Dissertação de Mestrado, Pontifícia Universidade Católica do Rio de Janeiro; Rio de Janeiro: 2010.

58 HUMAR, M.; ARCON, D.; UMEK, P.; SKARABOT, M.; MUSEVIC, I.; BREGAR, G.; Mechanical properties of titania-derived nanoribbons, Nanotechnology, 17 (2006) 3869-3872.

59 BYRNE, M.T.; MCCARTHY, J.E.; BENT, M.; BLAKE, R.; GUN'KO, Y.K.; HORVATH, E.; KONYA, Z.; KUKOVECZ, A.; KIRICSI, I.; COLEMAN, J.N.; Chemical Functionalisation of titania nanotubes and their utilisation for the fabrication of reinforced polystyrene composites, Journal of Materials Chemistry, 17 (2007) $2351-2358$.

60 CHENG, Q.L.; PAVLINEK, V.; HE, Y.; LI, C.Z.; LENGALOVA, A.; SAHA, P.; Facile fabrication and characterization of novel polyaniline-titanate composite nanotubes directed by block copolymer, European Polymer Journal, 43 (2007) 3780-3786.

61 KRALOVA, D.; SLOUF, M.; KLEMENTOVA, M.; KUZEL, R.; KELNAR, I.; Preparation of gram quantities of high-quality titanate nanotubes and their composites with polyamide 6, Materials Chemistry and Physics, 124 (2010) 652.

62 OHNO, T.; SARUKAWA, K.; TOKIEDA, K.; MATSUMURA, M.; Morphology of a $\mathrm{TiO}_{2}$ Photocatalyst (Degussa, P-25) Consisting of Anatase and Rutile Crystalline Phases, Journal of Catalysis, 203 (2001) 82-86.

63 CALliSteR, Jr.; Willian, D.; Ciência e engenharia de materiais: uma introdução. Tradução Sérgio Murilo Stamile Soares, Rio de Janeiro: Ed. LC, 2008 .

64 MANO, E.B.; MENDES, L.C.; Introdução a polímeros. Rio de Janeiro: Ed. Blucher, 1999. 
65 GOMES, B.M.C.; Produção e caracterização de filmes de polietileno de baixa densidade reforçados por nanocargas à base de $\mathbf{T i O} \mathbf{2}_{2}$. 2011, Dissertação de Mestrado, Pontifícia Universidade Católica do Rio de Janeiro; Rio de Janeiro: 2011.

66 OlIVEIRA, M.F.L.; Tenacificação em Nanocompósitos de Poliamida 6 e Argila; 2010, Dissertação de Mestrado, Universidade do Estado do Rio de Janeiro Janeiro; Rio de Janeiro: 2010.

67 VANDERVORST, P.; LEI, C.-H.; LIN, Y.; DUPONT, O.; DALTON, A.B.; SUN, Y.-P.; KEDDIE, J.E.; The fine dispersion of functionalized carbon nanotubes in acrylic latex coatings, Progress in Organic Coatings, 57 (2006) 91-97.

68 LIN, Y.; ZHOU, B.; FERNANDO, K.A.S.; LIU, P.; ALLARD, L.F.; SUN, Y.P.; Polymeric carbon nanocomposites from carbon nanotubes functionalized with matriz polymer, Macromolecules, 36 (2003) 7199-7204.

69 DEBLIECK, R.A.C.; VAN BEEK, D.J.M.; REMERIE, K.; WARD, I.M.; Failure mechanism in polyolefines: the role of crazing, shear yielding and the entanglement network, Polymer, 52 (2011) 2979-2990.

70 DOS SANTOS, M.S.; NOGUEIRA, V.P.; FERREIRA, M.; NETO, C.A.C.; REBELLO, J.M.A.; Utilização de método ultra-sônico na avaliação da degradação de náilon-11, $3^{\circ}$ Congresso Brasileiro de P\&D em Petróleo e Gás, Salvador - BA, outubro 2005.

71 MORGADO, E.; ABREU, M.A.S.; MOURE, G.T.; MARINKOVIC, B.A.; JARDIM, P.M.; ARAÚJO, A.S.; Characterization of nanostructured tiatnates obtained by alkali treatment of $\mathrm{TiO}_{2}$-Anatases with distinct crystal sizes, Chemistry Materials, 6 (2007) 665-676. 
9.

\section{Apêndice}

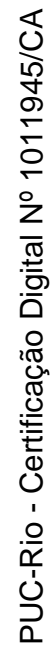

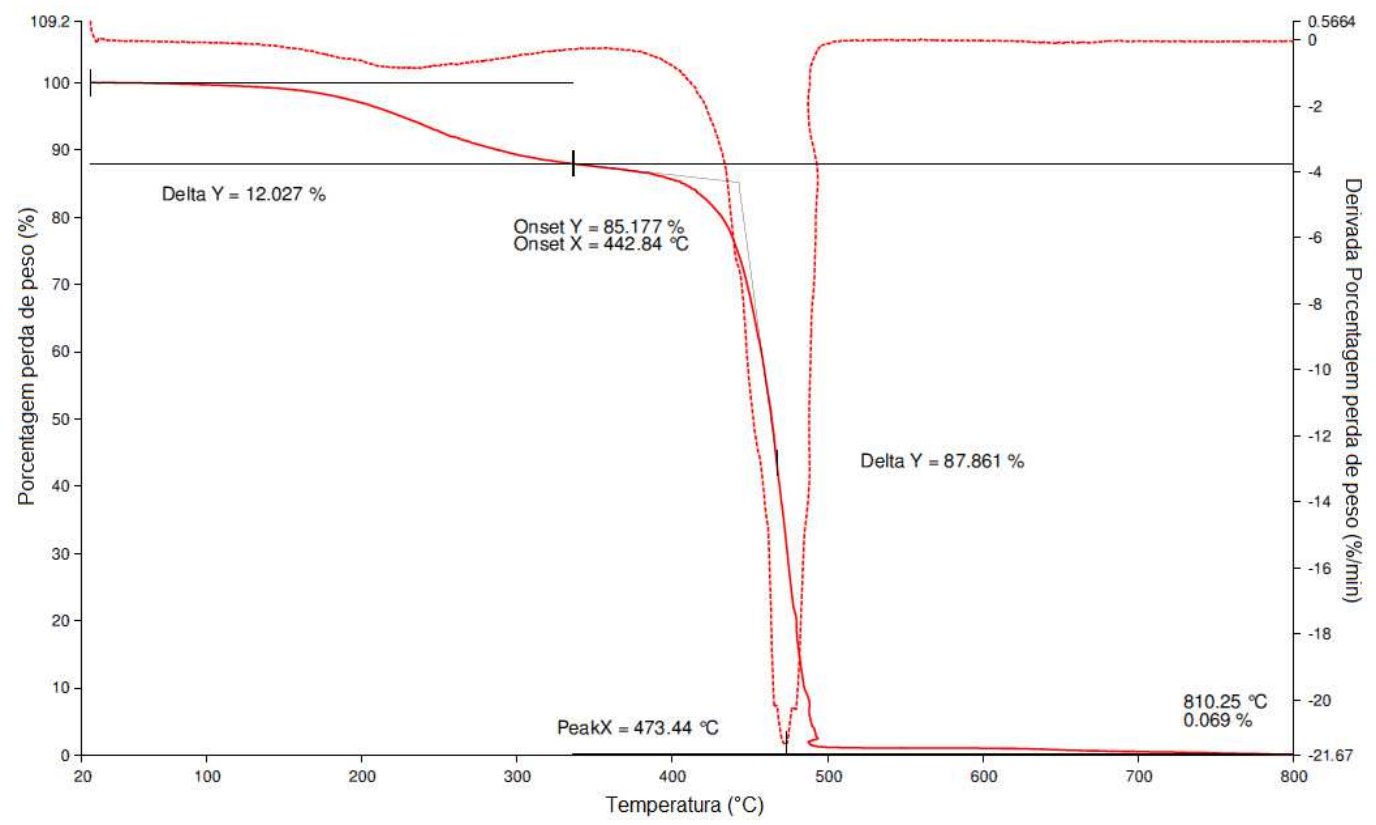

(a)

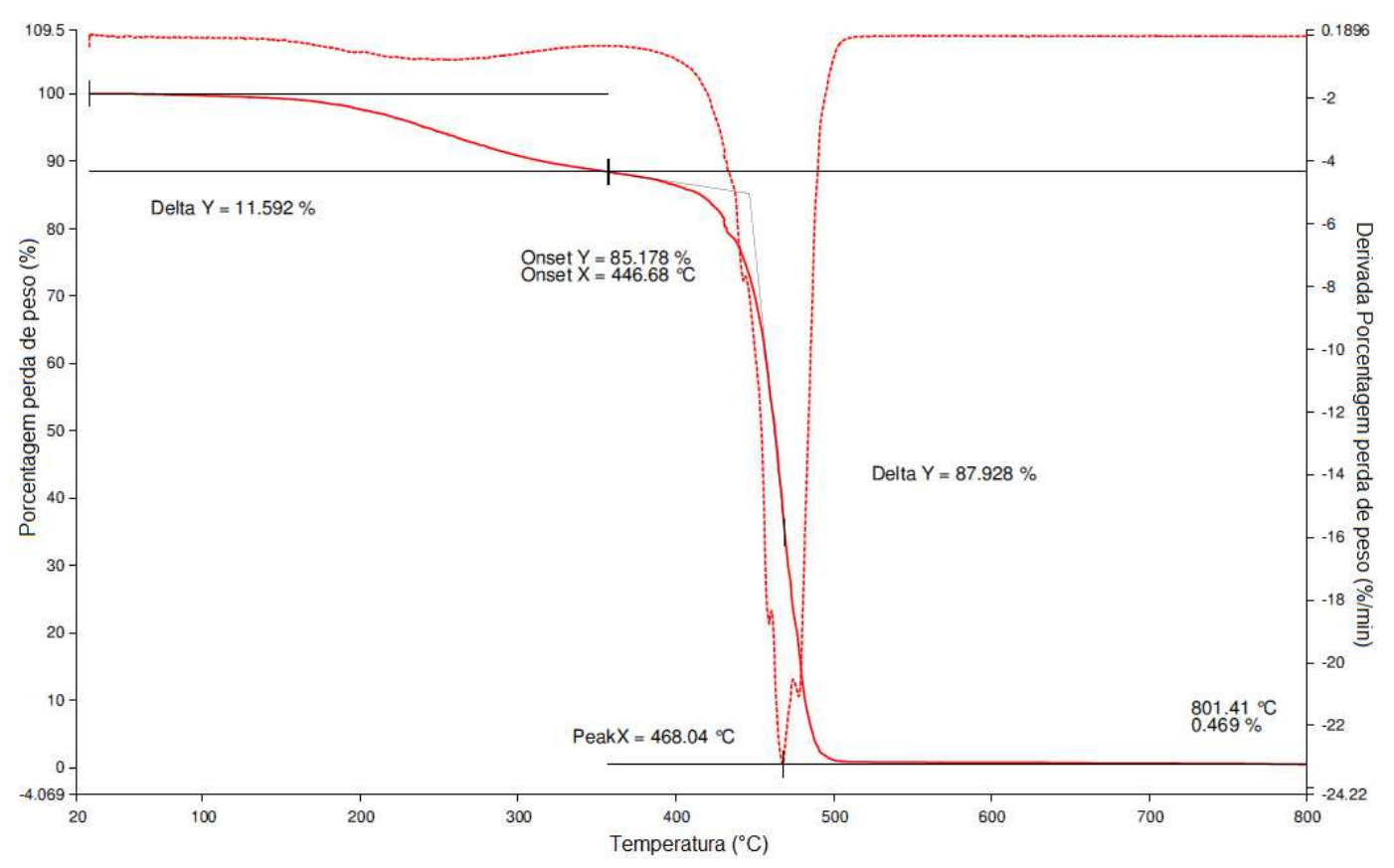

(b) 


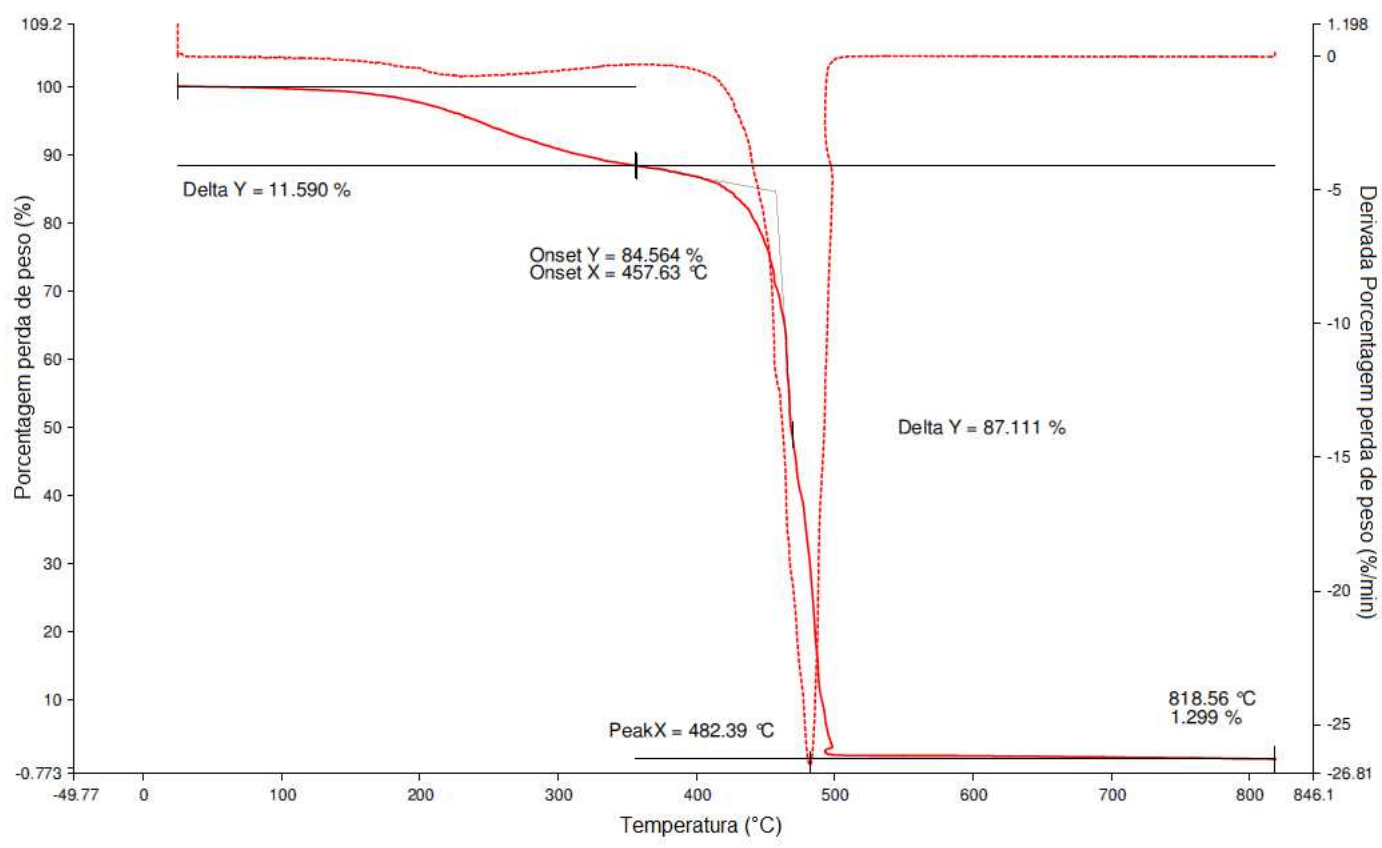

(c)

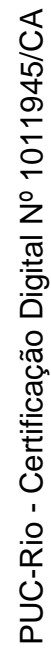

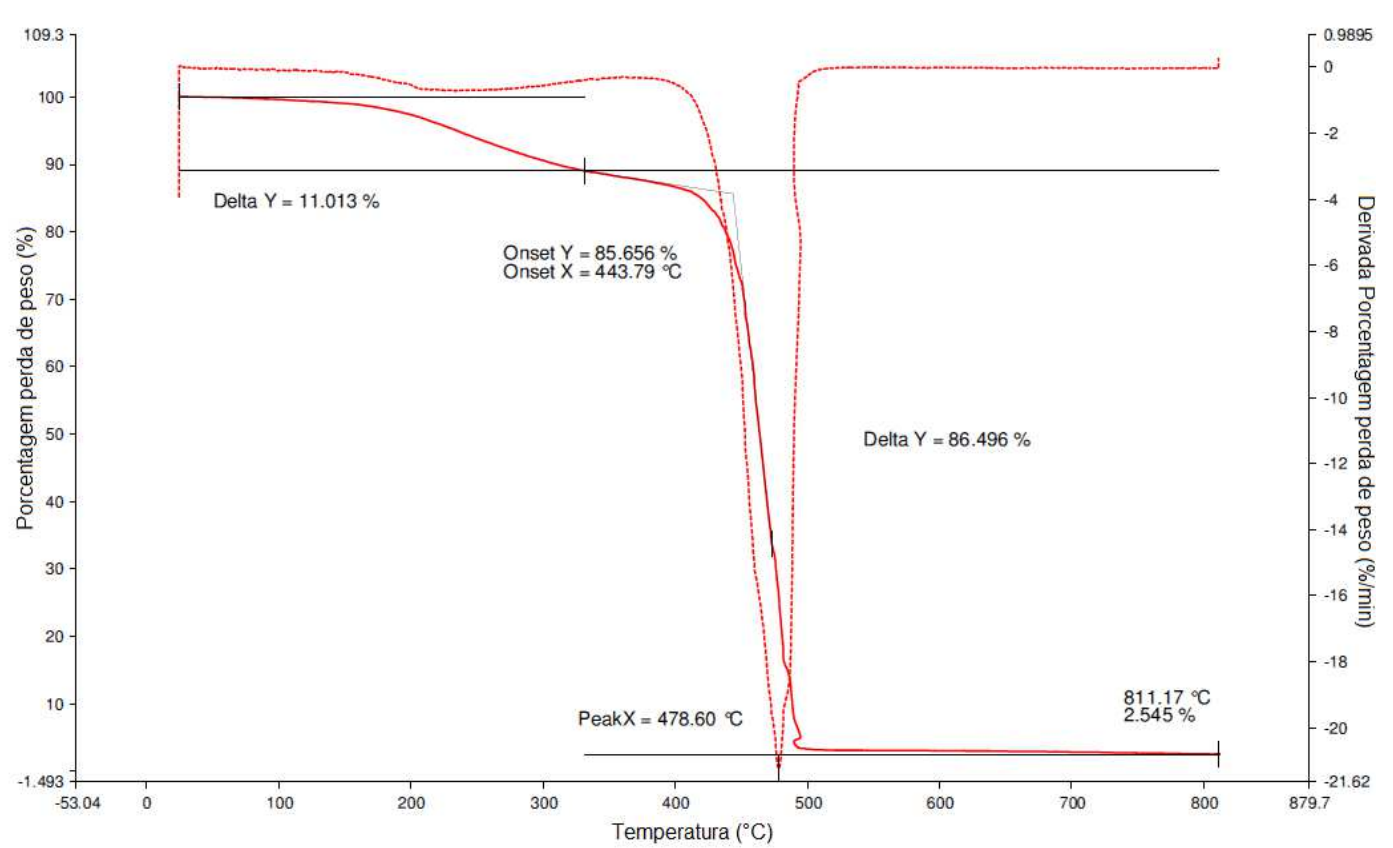

(d) 


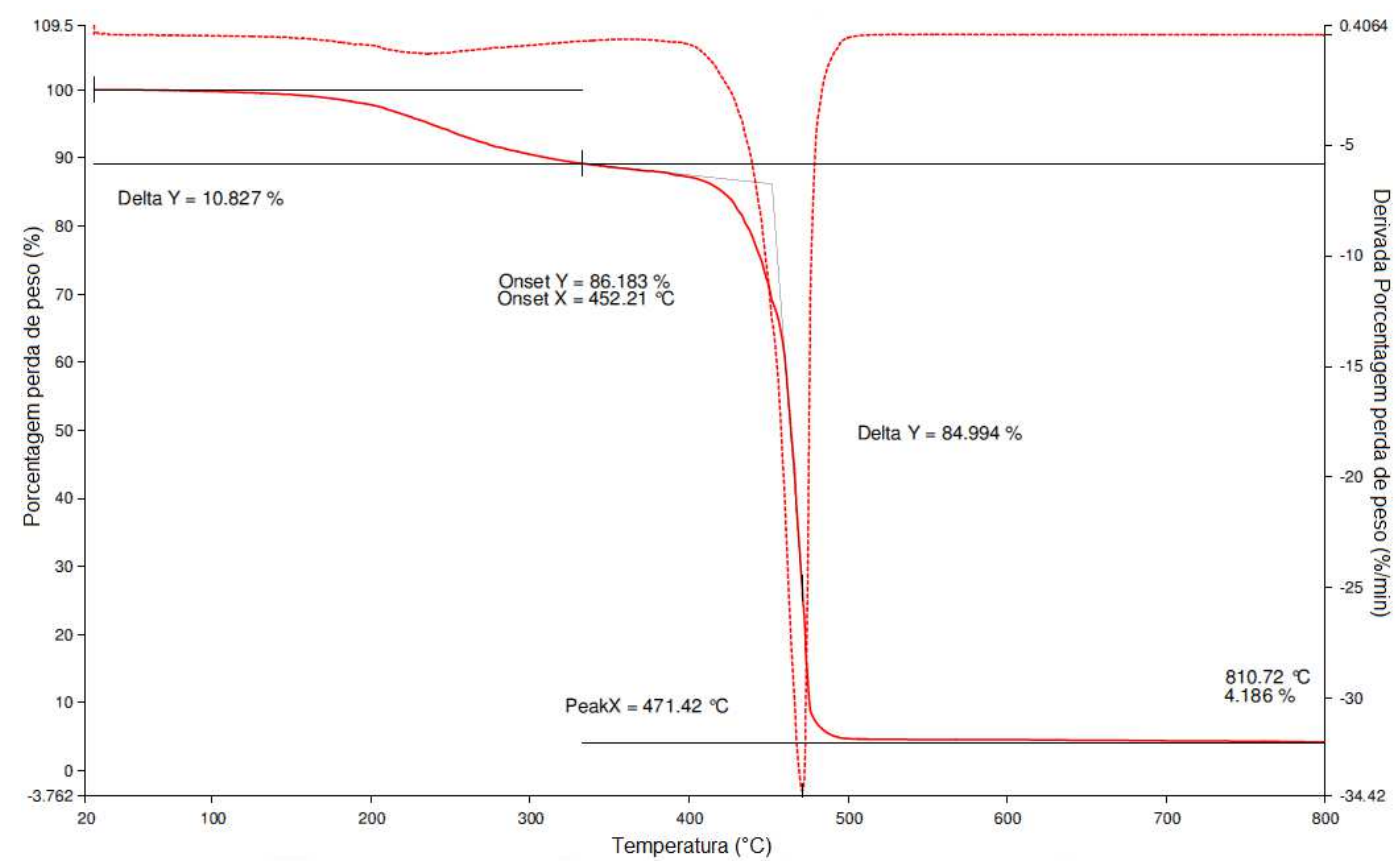

(e)

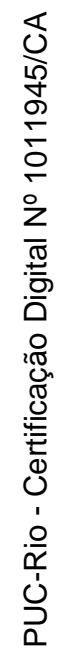

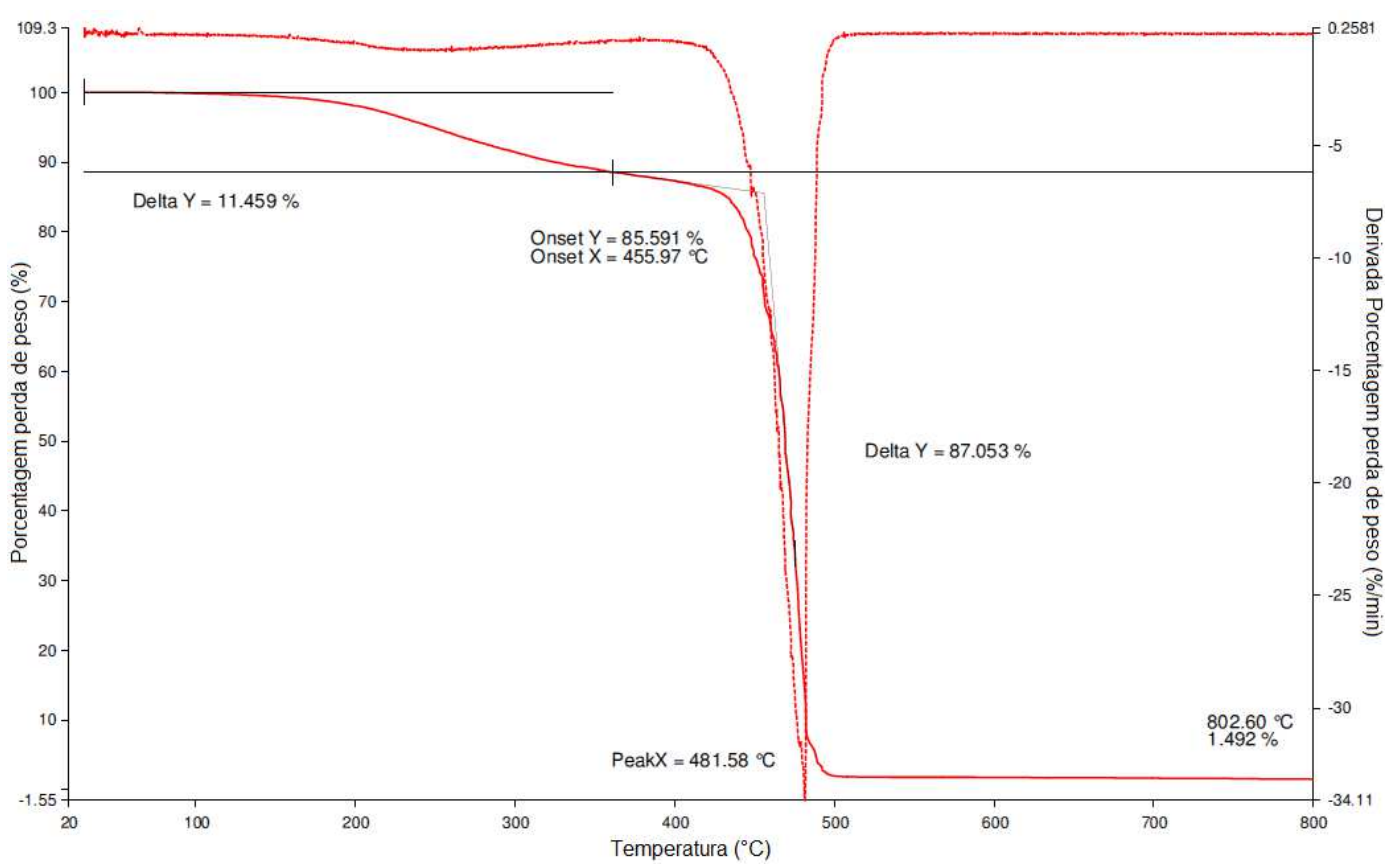

(f)

Figura 1 - Curvas termogravimétricas das amostras (a) A0, (b) Ap, (c) A1, (d) A2, (e) A3 e (f) A4. 